\title{
Institucionalidad y poder. La expulsión de los jesuitas y los colegiales reales del Real Colegio Mayor y Seminario de San Bartolomé, Santafé de Bogotá*
}

por

Juana María Marín Leoz ${ }^{1}$

Pontificia Universidad Javeriana, Bogotá-Colombia

La expulsión de la Compañía de Jesús de la Nueva Granada el 1 de agosto de 1767, no supuso la extinción del Colegio Seminario de San Bartolomé, dirigido por la Compañia desde su fundación en 1605. Así, el presente artículo se pregunta por las circunstancias y factores que contribuyeron a esta continuidad a partir del análisis de la tipología colegial de la institución, especificamente de la creación de las becas reales bartolinas en 1664 y la incorporación de las élites administrativas a la misma. En este escenario, los fondos documentales del Archivo Histórico Javeriano Juan Manuel Pacheco S. J. nos permiten analizar la dual y connivente gestión del Colegio Seminario que garantizó su continuidad a partir de 1767.

PALABRAS ClAVE: expulsión jesuita; colegios; élites administrativas; becas reales; institucionalidad.

Cómo citar este artículo / Citation: Marín Leoz, Juana María, “Institucionalidad y poder. La expulsión de los jesuitas y los colegiales reales del Real Colegio Mayor y Seminario de San Bartolomé, Santafé de Bogotá", Revista de Indias, LXXVIII/273 (Madrid, 2018): 459-503. https://doi.org/103989/revindias.2018.014.

* Artículo resultado del Proyecto de investigación "La familia bartolina. Los colegiales del Real Colegio Mayor y Seminario de San Bartolomé, 1742-1792”, financiado por la Oficia de Investigación (OFI) de la Vicerrectoría de Investigación de la P. Universidad Javeriana como parte de la Convocatoria Interna "Apoyo a proyectos de Investigación a partir de los fondos documentales del Archivo Histórico Javeriano”, convocatoria n. ${ }^{\circ}$ 003, año 2013.

Los primeros resultados de este proyecto de investigación no hubieran visto la luz sin el trabajo, dedicación y apoyo constante de Érika Parrado Pardo, Andrés Farfán Castillo y Jorge Mestre Acuña, magníficos asistentes de investigación. Mi más sincero agradecimiento y reconocimiento.

1 juana.marin@javeriana.edu.co, ORCID iD: http://orcid.org/0000-0001-8292-7296. 


\section{INTRODUCCIÓN}

La expulsión de la Compañía de Jesús de tierras hispánicas en 1767 sacudió profundamente la sociedad, transformando la realidad socio-política de los territorios españoles a ambos lados del Atlántico ${ }^{2}$. Centrándonos en el escenario educativo del virreinato de la Nueva Granada, el extrañamiento jesuita supuso, por un lado, la extinción de la Universidad Javeriana ${ }^{3}$ y, por el otro, una nueva andadura en el Colegio Seminario de San Bartolomé, que a los pocos días de la expulsión reabrió sus puertas, eso si, sin jesuitas. Una realidad que respondía a las soluciones que se materializaron para el grueso de los colegios y seminarios jesuitas tras la Expulsión. Así, o bien fueron extinguidos, inmediatamente o tras años de «languidecimiento» en nuevas manos; o designados a la dirección de otras órdenes, especialmente dominicos y agustinos; o traspasados a la gestión al clero secular, bajo el patronato virreinal, como en el caso bartolino ${ }^{4}$.

En este escenario concreto, y según el análisis de Villalba Pérez 5 , San Bartolomé se particularizó por el hecho de que su pervivencia rompió totalmente con la realidad colegial jesuita, tanto en la forma como en el fondo, una conclusión que el presente artículo contextualiza y matiza a partir de un análisis que trasciende el escenario de la expulsión y se retrotrae en el tiempo hasta mediados del siglo XVII, preguntándose por la presencia y protagonismo del poder secular en la institución educativa jesuita y por las continuidades que éste generó y moldeó en la renovada situación.

${ }^{2}$ Las causas de la expulsión de la Compañía de Jesús deben analizarse desde unas coordenadas que trasciendan los tradicionales pretextos esgrimidos por el Dictamen del fiscal Campomanes, materialización de la «vulgata antijesuita» — Guasti, 2014: 77—, e insertarse en una larga y conflictiva lucha política en el marco del absolutismo y la ilustración de las monarquías europeas, inmersas en la dialéctica sobre la concepción del poder absoluto y su relación con la Iglesia. En este escenario, «una orden [la Compañía] con una organización internacional y cuyo cuartel general se hallaba fuera de España se consideraba intrínsecamente incompatible con el absolutismo» —-Lynch, 1991: 252-, una realidad que cimentó el crecimiento de la animadversión jesuita en España y la materialización de su expulsión en 1767. Una resolución no exclusiva de la monarquía hispánica sino que fue antecedida por la expulsión de Portugal en 1759 y de Francia en 1763. Para ampliar el análisis sobre las causas y consecuencias de la Expulsión véase García Cárcel, 2003: 189-196 y Ferrer Benimelli, 2000; 2014. Rey Fajardo, 2014, para el territorio neogranadino.

3 Sobre el proceso de extinción de las universidades jesuitas véase Rodríguez Cruz, 1992. Para el caso javeriano, Rey Fajardo, 2010.

4 Villalba Pérez, 2003.

5 Ibidem: 58. 


\section{EXPULSIÓN DE LA COMPAÑÍA}

Al momento de la expulsión, en agosto de 1767, la Compañía de Jesús disponía en Santafé de tres casas. La principal, el Colegio Máximo, dónde funcionaba la Universidad Javeriana con sus cátedras de gramática, filosofía, teología y derecho, y al que pertenecían 31 sacerdotes, 38 escolares y 26 hermanos coadjutores ${ }^{6}$. La residencia y noviciado en el que vivían tres sacerdotes y tres hermanos coadjutores en el barrio de las Nieves ${ }^{7}$; y, por último, el Real Colegio Mayor y Seminario de San Bartolomé que era un seminario-convictorio ${ }^{8}$, en el que estudiaban y residían aproximadamente un centenar de estudiantes venidos de todas las regiones del virreinato. Éste fue inaugurado el 18 de octubre de 1605 como sucesor del Colegio Seminario de San Luis — fundado en 1581 - y del Colegio Máximo Ignaciano — que acababa de ser establecido por la recién llegada Compañía de Jesús - ${ }^{9}$. Los jesuitas, a solicitud del arzobispo Bartolomé Lobo Guerrero, se hicieron cargo también de la nueva institución con el objetivo de regir la educación de los 70 jóvenes pertenecientes a las principales familias de la capital y materializar la institucionalización de un verdadero seminario diocesano siguiendo las directrices del Concilio de Trento $^{10}$. En este sentido, además, la cesión por parte del

${ }^{6}$ DRAE, Coadjutor: Entre los regulares de la Compañía de Jesús el que no hace profesión solemne, http://lema.rae.es/drae/?val=coadjutor.

7 Groot, 1869, vol. III: 508.

8 DRAE, Convictorio: En los colegios de jesuitas, departamento donde viven los educandos, http://lema.rae.es/drae/?val=convictorio. A pesar de que el general Acquaviva no era favorable, finalmente, en 1610, se abrió el convictorio con el fin de contar con un semillero propio en caso de tener que entregar el seminario al arzobispo. Pacheco, 1959: vol. III: 128. Nacido en el seno de familia napolitana, Acquaviva ingresó en la Compañía de Jesús en 1567, en la que hizo una rápida y ascendente carrera. En 1576, fue elegido provincial de Nápoles y en 1579 fue designado para la Provincia Romana. En 1581, auspiciado por el Papa Gregorio XIII, fue nombrado prepósito general de la Compañía. Su largo generalato, 34 años estuvo a la cabeza de la Compañía, cristalizó en múltiples tensiones internas y enfrentamientos faccionarios, así como en duras acusaciones de absolutismo y «verticalismo» en su gestión. Acquaviva apostó por la reforma interna de la orden con el objetivo de reforzar la espiritualidad y la unidad jesuita, así como por la defensa de la identidad ignaciana frente a las presiones de las cortes europeas, del Papado y de las injerencias de otras órdenes en la disciplina interna jesuita. O'Neill, 2001, vol. IV: 1614-1615.

9 Restrepo, 1928. Silva Olarte, 2002: 35.

${ }^{10}$ La última reunión del Concilio de Trento, entre 1561 y 1562, impuso la fundación de Seminarios para la formación del clero. Unas instituciones que se debían caracterizar por «la dependencia disciplinar y económica del obispo, vida en común entre profesores y alumnos y una enseñanza más práctica de la teología». Así mismo, desde el Concilio se instó a las diócesis menos dotadas a buscar la cooperación de la Compañía de Jesús, garante de la edu- 
arzobispo de la dirección del colegio a la Compañía supuso que la rectoría del mismo se subordinase al superior jesuita, relacionando, inevitablemente, el destino de ambas direcciones ${ }^{11}$.

Sobre la expulsión de la Compañía de Jesús de la Nueva Granada se conservan dos relaciones anónimas aunque atribuidas, la primera, al padre José Yarza, último rector jesuita de San Bartolomé, y, la segunda, a Ignacio Duquesne, estudiante de teología en San Bartolomé en el momento de la expulsión. Dos relatos, recogidos por el padre Pacheco a principios del siglo XX, que nos permiten aproximarnos a cómo sucedió el proceso de extrañación ${ }^{12}$. Así, el 7 de julio de 1767, el virrey Pedro Messía de la Cerda recibió el decreto de expulsión de la Compañía de Jesús de los dominios españoles junto con la Instrucción del Conde Aranda. En consecuencia, el virrey reunió a su consejo privado y le dio a conocer las órdenes reales, señalando el 1 de agosto como la fecha para proceder a ellas. Para este fin, fueron designados 6 conjueces ejecutores, dos por cada una de las casas jesuitas. Para el Colegio Máximo fueron señalados el oidor Antonio Berástegui y Saracho y el abogado y protector de indios Francisco Antonio Moreno y Escandón, para el Seminario de San Bartolomé el oidor Juan Francisco Pey Ruiz y el provisor del arzobispado Gregorio Díaz Quijano y, finalmente, para el noviciado de las Nieves el oidor Luis Carrillo de Mendoza y el fiscal José Antonio Peñalver Vequé13.

Detengámonos precisamente en estos conjueces, con el fin de identificarlos, analizar qué institución santafereña fue la que «protagonizó» la expulsión y si estos conjueces tenían algún vínculo con la Compañía de Jesús y/o el seminario bartolino. Así, el oidor Berástegui y Saracho, limeño nacido en 1704, llegó a Santafé en 1733 para realizar la práctica legal en su audiencia. Desde este año hasta 1737, fue asesor del presidente Rafael Eslava, asesoría que lo llevó, en 1740, a repetir empleo con el virrey Sebastián Eslava, hermano del anterior. Nombrado oidor supernumerario de la audiencia dos años después, no fue hasta 1744 que entró a ocupar la plaza, aunque permaneció

cación media y cristiana de niños y jóvenes, para la gestión y organización de las nuevas instituciones seminarias. Delgado Criado, 1993: 75-76. Vergara Ciordia, 2005: 239-240. Pérez Puente, 2013: 86.

11 El Capítulo III de las Constituciones y testimonio de erección del Colegio Seminario de San Bartolomé. Capítulo 1, Archivo Histórico Javeriano Juan Manuel Pacheco S. J., Bogotá (AHJJMP), Fondo Primera Época (FPE), B1-ES1-EN1-CP26-DVD 01, doc. 636, fs. 6r-6v, recoge el encargo del arzobispo de Santafé a la Compañía de Jesús de la nueva institución bartolina.

12 Pacheco, 1959, vol. III: 507.

13 Ibidem: 511. 
en Cartagena, junto al virrey, hasta 1750. Este año, pasó a Santafé donde ejerció como oidor hasta su fallecimiento en $1776^{14}$. Por su parte, Francisco Antonio Moreno y Escandón, nacido en Mariquita, Nueva Granada, en 1736, fue colegial de San Bartolomé en 1749 y obtuvo grados de bachiller y maestro por la Universidad Javeriana ${ }^{15}$. Profesor en la misma, comenzó su labor profesional como practicante de la audiencia santafereña, donde fue nombrado fiscal protector de Indios en 1765, cargo que ejercía en el momento de la expulsión ${ }^{16}$.

Juan Francisco Pey Ruiz llegó a Santafé en el año 1748 como oidor supernumerario de la audiencia, empleo que ejerció hasta su jubilación en 1786. Casado con la santafereña María Andrade Insinillas, su relación con la Compañía, a primera vista, se concretaba en que tanto su cuñado, Manuel Andrade Insinillas, como sus dos hijos mayores, Juan de Dios y Juan Bautista Pey Andrade, se habían formado en las aulas de San Bartolomé, institución a su cargo esa madrugada del primero de agosto de 176717 . Su compañero en la misión, José Gregorio Díaz Quijano, fue también colegial de San Bartolomé en 1731 y se doctoró en teología por la Universidad Javeriana ${ }^{18}$. Miembro del cabildo eclesiástico santafereño, al que ingresó como racionero en 1749 y en el que fue designado como tesorero en 1759, era provisor general del arzobispado en el momento de la extrañación ${ }^{19}$.

Finalmente, Luis Carrillo de Mendoza, nacido en Sigüenza en 1705, llegó a Panamá en 1726 como oidor de su audiencia y fue enviado a Santafé, también como oidor, tras la disolución de la misma en 1752. Ejercía este cargo en el momento de la expulsión y permaneció en él hasta su fallecimiento en

14 Vázquez Varela, Ainara, "De la primera sangre de este reino”. Composición de las instituciones de justicia y gobierno de Santafé de Bogotá, 1700-1750. Catálogo Biográfico de 2008, 2 vols., Universidad de Navarra (Pamplona), vol. II: 358-360.

15 Grado de bachiller, 27 de junio de 1750; grado de maestro en filosofía, 25 de julio de 1752; y grado de doctor en sagrada teología, 27 de julio de 1755. Rey Fajardo, 2013, vol. II: 604-605.

16 Burkholder y Chandler, 1982: 222-223.

17 Marín Leoz, Juana María, La élite rectora de la capital. Composición de las instituciones político-administrativas de Santafé de Bogotá durante el gobierno del virrey Pedro Mendinueta y Múzquiz, 1797-1803. Catálogo Biográfico, de 2007, Universidad de Navarra (Pamplona), vol. II: 76-78.

18 Grado de maestro el 26 de julio de 1737 y grado de doctor el 26 de julio de 1740 . Rey Fajardo, 2013, vol. II: 618-619.

19 Vázquez Varela, Ainara, "De la primera sangre de este reino”. Composición de las instituciones de justicia y gobierno de Santafé de Bogotá, 1700-1750. Catálogo Biográfico de 2008, 2 vols., Universidad de Navarra (Pamplona), vol. II: 113-114. 
$1772^{20}$. El también empleado de la audiencia, el fiscal José Antonio Peñalver Vequé, llegó a Santafé en el año 1731 como protector de indios y, tres años después, se hizo cargo de forma interina de la fiscalía. Mantuvo la interinidad hasta 1756, fecha en la que se le ratificó el empleo de forma oficial. Por lo tanto, el conjuez Peñalver era fiscal de la audiencia de Santafé la madrugada del primero de agosto cuando se ocupó de la expulsión en el Noviciado de la Nieves.

En definitiva, cinco de los seis conjueces encargados de la expulsión eran miembros de la audiencia de Santafé, lo que convirtió a esta institución en la compañera, y garante, del virrey en la ejecución de la real orden. Una presencia mayoritaria que se completa con la participación del cabildo eclesiástico, el gobierno diocesano sede vacante, de la mano de su provisor general. Dos instituciones que, además, y centrándonos en San Bartolomé, respondían a la naturaleza dual de la institución bartolina: Seminario en el que se formaban estudiantes para ser sacerdotes y Colegio para la formación secular. Así mismo, es interesante subrayar el hecho de que la mitad de los conjueces tenía vínculos con la institución bartolina jesuita, Moreno y Díaz Quijano en primera persona, ya que fueron colegiales del mismo, y Pey de la mano de su cuñado y sus hijos, el pequeño de los cuales, Juan Bautista, era colegial en el momento de la expulsión ${ }^{21}$.

Volvamos, en este punto, al relato de Pacheco sobre el extrañamiento. Desde la medianoche del 1 de agosto, la guardia virreinal rodeó los tres edificios jesuitas y los conjueces, en conformidad con el artículo segundo de la Instrucción, se dirigieron a los puntos señalados al despuntar el día.

Los del colegio Máximo golpearon el portón y tocaron la campañilla bajo pretexto de llamar para una confesión. Inmediatamente fue abierto el portón. El oidor Berástegui y el fiscal Moreno, seguidos de escribanos, testigos y soldados, se dirigieron al cuarto del padre provincial Manuel Balzategui, quien ya les esperaba. A toque de campana fue reunida toda la comunidad a la sacristía (...) Estando allí, el Oidor les intimó, en presencia del escribano y testigos, el real decreto, leyéndoselo de verbo ad verbum, e inteligenciados de él, y exhortados a la resignación y obediencia, se le pidió al provincial que entregase todas las llaves pertenecientes al colegio, las del archivo, librería, arcas y escritorio, lo que ejecutó puntualmente entregando cuantas había. Después de esto los padres fueron arrestados y los jueces continuaron haciendo rigoroso escrutinio e inventario de cuanto se encontraba en las habitaciones, arcas, alacenas y demás ${ }^{22}$.

20 En el año 1771 fue nombrado oidor de la audiencia de Charcas, pero falleció antes de emprender su viaje a su nuevo destino. Burkholder y Chandler, 1982: 72-73.

21 Juan Bautista Pey Andrade vistió beca de colegial real el 13 de abril de 1766, iniciando sus estudios en el Colegio Seminario de San Bartolomé. Restrepo, 1928: 348.

22 Pacheco, 1959: 515-516. 
Estas mismas diligencias se realizaron en el Noviciado y en el Colegio Seminario de San Bartolomé. En éste, tras reunir e informar de lo que estaba aconteciendo a los cuatro jesuitas que se encontraban en el convictorio -el rector José Yarza, el ministro José Joaquín Leal, el pasante Francisco de la Cerda y el hermano coadjutor Matías Pirle-, los comisionados, conforme a la orden del virrey, dieron permiso a los colegiales para salir, informándoles de las providencias que se habían tomado con sus maestros y, sobre todo, de que dentro «de pocos días el colegio estaría organizado con otros preceptores para que pudieran continuar sus estudios $»^{23}$.

En este mismo escenario, el virrey solicitó al deán del cabildo sede vacante, que era el depositario del patronato seminario, que organizara y seleccionara, por lo menos interinamente, a las personas que iban a encargarse de suceder a los jesuitas en la administración del colegio. Una organización que respondía a lo dispuesto en las instrucciones reales de «proveer en el mismo instante a sustituir a los maestros jesuitas con eclesiásticos seculares que no sean de su doctrina» ${ }^{24}$.

La demanda de una rápida designación de individuos que se hicieran cargo del Colegio Seminario se resolvió, efectivamente, con celeridad. A pesar de que durante el primer mes la organización de la institución es un tanto complicada en el recambio de las primeras autoridades, vemos que desde los primeros días el cabildo eclesiástico, en virtud de su patronato sobre el Seminario, aparece como el nuevo agente directivo del mismo. Así, el 4 de agosto de 1767, el nuevo rector Antonio Isabella da curso a la solicitud de beca seminaria de Juan Nepomuceno Ramírez de Arellano, una beca que había sido concedida por el provisor Gregorio Díaz Quijano el 19 de junio del mismo año ${ }^{25}$. Por lo tanto, 3 días después de la expulsión jesuita, la maquinaria administrativa sigue en marcha, con otros nombres, sin adscripción regular, pero manteniendo el funcionamiento y la estructura organizativa de la, ya, antigua institución jesuita.

En este sentido, agosto será un mes de acondicionamiento y ajuste al cambio. De hecho, los documentos nos muestran dos rectores en el mismo mes. Durante las dos primeras semanas, el cura de la catedral Antonio Isabella se hará cargo de la rectoría y, desde el 20 de agosto, Antonio Javier Ignacio Mena y Felices, como nuevo rector, Diego Tirado, como vicerrector, Agustín Durán Collogos, como secretario, y Manuel Andrade, como pasante,

23 Groot, 1869, vol. II: 87.

24 Ibidem: 554.

25 Concesión de Beca Seminaria a Juan Nemopuceno Ramírez Arellano, Santafé, 4 de agosto de 1767, AHJJMP, Fondo Colegio San Bartolomé (FCSB), rollo 29, caja 56, f. 153r. 
dirigirán la transición ${ }^{26}$. Los nuevos directivos del Colegio Seminario, además de pertenecer al cabildo eclesiástico - Mena Felices era Maestrescuela y Durán canónigo ${ }^{27}$ - eran, sobre todo, antiguos colegiales de la institución bartolina: Durán fue colegial real en octubre de 1707, misma beca que vistió Mena Felices en abril de 1720 y Andrade fue convictor en octubre de 1755, condición desde la que solicitó, y le fue concedida, una beca seminaria en octubre de $1757^{28}$. Esta presencia de «hijos de la institución» en la nueva dirección de la misma fue aprobada por el virrey bajo la premisa y juramento de «no profesar ni enseñar, pública ni privadamente la doctrina jesuita, so pena de extrañamiento» y bajo la estricta supervisión del nuevo regente de estudios, Francisco Antonio Moreno y Escandón, a la sazón, otro excolegial de la institución jesuita ${ }^{29}$.

La expulsión de la Compañía marca el inicio de un período de reformas y trasformación del programa educativo y la estructura pedagógica de la institución bartolina, que, paralelamente, abrirá una ardua disputa en torno a la propiedad del patronato bartolino tras la salida jesuita. El extrañamiento convirtió a San Bartolomé en el principal escenario, y laboratorio, de los proyectos de reforma educativa, encabezados por la Junta de Temporalidades ${ }^{30}$ y por

${ }^{26}$ Cartas de legitimidad de pretendientes al Colegio Seminario de San Bartolomé, agosto-septiembre de 1767, AHJJMP, FCSB, rollo 4, fs. 158-197 y 203-210.

27 Jaramillo Mejía, 1996: 3-4. Vázquez Varela, Ainara, "De la primera sangre de este reino”. Composición de las instituciones de justicia y gobierno de Santafé de Bogotá, 17001750. Catálogo Biográfico de 2008, 2 vols., Universidad de Navarra (Pamplona), vol. II: 229. La confusión de estos primeros meses es tal, que en los diferentes documentos encontramos nombramientos de rectores que se superponen. Así, Hernández de Alba recoge un documento en el que se nombra a Durán como primer rector seglar en octubre de 1767, documento que se contrapone con la información recogida en las cartas de legitimidad correspondientes a los meses finales del año 1767, así como a lo expuesto por William Jaramillo Mejía en su investigación.

28 Restrepo, 1928: 140-150, 205 y 316. Concesión de beca seminaria a Manuel Andrade, Santafé, 10 octubre de 1757, AHJJMP, FCSB, rollo 29, caja 56, fs. 119r-120r. A pesar de que las fuentes presentan a Tirado como miembro del cabildo eclesiástico e «hijo del colegio», no hemos hallado datos concretos sobre él, más allá de que fue hermano del que fuera rector de San Bartolomé entre 1760 y 1767, el jesuita Lorenzo Tirado. Jaramillo Mejía, 1996: 3. Rey Fajardo y Mora González, 2008: 208.

29 Decreto de nombramiento de Francisco Antonio Moreno y Escandón como regente de estudios, 1767, Hernández de Alba, 1969: 322, decreto n. ${ }^{\circ}$ 199. En relación a la autoridad y poder de Moreno, es significativo que el primer rector de San Bartolomé fue su cuñado Antonio Isabella. Jaramillo Mejía, 1996: 159 y 799.

30 Presidida por el virrey, encargada de inventariar, ocupar, contratar y vender todos los bienes de la expulsa, y luego extinta, Compañía de Jesús, así como la encargada del cumplimiento de todo los dispuesto. Silva Olarte, 2004: 123. 
Francisco Antonio Moreno y Escandón, nombrado nuevo director de estudios. El proyecto de Moreno apostaba por la secularización y reorganización de los estudios superiores. Así, en primer lugar, se desmanteló, paulatinamente, el programa de estudios bartolino basado en la jesuita Ratio Studiorum ${ }^{31}$ y, en segundo, se apostó por la reestructuración de los estudios generales impartidos en los dos colegios mayores de la capital, con el objetivo de construir una universidad pública de estudios generales a semejanza de las de México y Lima y financiada con los recursos de la extinta Compañía. El plan de Moreno y Escandón tuvo que enfrentarse a duros obstáculos y oposiciones materializados tanto en la ausencia de un escenario adecuado para la concreción de una universidad pública en el territorio neogranadino como, y sobre todo, en la férrea oposición de la comunidad dominica desde la universidad tomista. La oposición de estos últimos fue tan fuerte, cimentada en la preservación de su autonomía en la enseñanza, así cómo en la apuesta por monopolizar la educación superior en la Nueva Granada ${ }^{32}$, que, finalmente, en 1779 el plan de Moreno se paralizó y desarmó. Por tanto, mientras en San Bartolomé se adecuaba a un nuevo escenario educativo y pedagógico no jesuita, el resto de instituciones retomaron sus modelos educativos anteriores ${ }^{33}$.

31 La Ratio atque Studiorum Societate Jesu, promulgada en Roma el 8 de enero de 1599, bajo el mandato del general Claudio Acquaviva, concretó un ordenamiento didáctico-escolástico que, trascendiendo lo teórico en pos de una finalidad práctica de dirección del ministerio, conjugaba una serie de reglas de organización y guía de todos los dedicados de la enseñanza en las instituciones educativas jesuitas, desde el provincial hasta los bedeles, pasando por profesores y colegiales. Este corpus normativo conjugaba lo espiritual, lo pedagógico y lo didáctico para la organización de la estructura de los colegios, la división de los cursos, el horario de las clases, la materia de enseñanza, los autores a estudiar, los exámenes y los ejercicios académicos. La Ratio se convirtió en el verdadero directorio espiritual del estudiante cristiano en el orbe académico jesuita y estuvo vigente hasta la extinción de la Compañía en 1773, una inalterabilidad, a pesar de las exigencias de los tiempos, en la que se sustenta la más repetida crítica al ordenamiento educativo jesuita. O’Neill, 2001, vol. IV: 3292-3297. Sobre su naturaleza, razón de ser e implantación véase Bertrán-Quera, 1984 y Gil, 2002. Para el territorio neogranadino, Rey Fajardo, 55 (Braga, 1999).

32 Soto Arango, 2004b: 48.

33 El plan de Moreno y Escandón, denominado Método provisional e interino de los estudios que han de observar los Colegios de Santafé, por ahora, y hasta tanto que se erige universidad pública o su Majestad dispone otra cosa, se fundamentaba en el realizado por Pablo de Olavide y la reforma de la Universidad de Alcalá. Soto Arango, 2004a: 37-39. A pesar de su corta aplicación, entre 1774 y 1779, el plan de Moreno asentó las bases de nuevos saberes y formas de conocimiento entre una generación de jóvenes estudiantes, familiarizándolos con la filosofía moderna y con la enseñanza de «conocimientos útiles» ligados a la prosperidad del Reino. Será precisamente esta «juventud escolar» formada en el Plan de Moreno la protagonista de la madurez ilustrada neogranadina y de las múltiples disputas po- 
Paralelamente a las propuestas y disputas en torno al plan de estudios, la titularidad del patronato bartolino postjesuita se convirtió también en contencioso entre aquellos que consideraban que el patronato correspondía al arzobispo y quienes defendían que era preeminencia del virrey. Esta contienda configuró dos facciones enfrentadas, la conformada por el virrey y la Junta de Temporalidades, que defendía el patronato real en el nombramiento de becas y en la designación de directivas del colegio y la del arzobispo y el cabildo eclesiástico, que denunciaba la constante usurpación de sus derechos patrimoniales por parte del virrey.

El centro de la disputa se relacionaba con el hecho de que, en virtud de la Constituciones fundacionales, los jesuitas eran los patronos de la institución por lo que, una vez expulsados, la misma pasaba al Rey como sucesor de todos los derechos de los expulsos. Esto implicaba, en palabras del gobierno arzobispal, «un despojo de los derechos patrimoniales del arzobispo en la gestión del Seminario y en la designación de las becas seminarias» ${ }^{34}$. Esta dualidad mostraba la complicación jurisdiccional de San Bartolomé, colegio de patronato real heredado de los jesuitas, incorporado al Seminario conciliar cuya dirección, en virtud de lo dispuesto en el Concilio de Trento, correspondía al arzobispo y cabildo eclesiástico ${ }^{35}$. Por tanto, la discusión sobre el patronato llevaba imbricada la dualidad Seminario Colegio que caracterizaba a la institución desde su fundación y respondía a que cada potestad quería mantener su derecho patrimonial sobre su escenario bartolino ${ }^{36}$.

A pesar de los cambios, disputas, reformas y contrarreformas que sufrió San Bartolomé tras la expulsión, la institución siguió en marcha, respondiendo a la voluntad de la Corona de no suspender la educación bartolina, sino de reemplazar la antigua jerarquía administrativa y el cuerpo de maestros ${ }^{37}$. Por lo tanto, desde agosto de 1767 prosiguió la labor educativa de jóvenes que ingresaban al Colegio Seminario en calidad de colegiales, todos ellos, como se puede observar en la tabla 1, hijos, nietos y sobrinos de los miembros de la audiencia, el cabil-

lítico sociales del período de la tardo colonia y de los primeros compases del proceso independentista. Para profundizar en las reformas educativas y la configuración de un escenario dialéctico entre modernidad y tradición véase Silva Olarte, 2002: 64-71; 2004: 121-125; 2005.

34 Salazar, 1946: 362.

35 Ibidem: 365.

36 Esta confusión llegó a su momento culminante durante el mandato del arzobispo virrey Caballero y Góngora, ya que éste, durante su ejercicio, acaparó ambas dignidades. Caballero y Góngora nombró como rector a la figura que dirigirá el Colegio Seminario de San Bartolomé entre 1786 y 1804, Manuel Andrade Insinillas, primer pasante del Colegio tras la expulsión de la Compañía. Jaramillo Mejía, 1996: 35-36.

37 Silva Olarte, 2004: 121. 


\begin{tabular}{|c|c|c|c|c|c|c|c|c|c|c|c|c|c|}
\hline 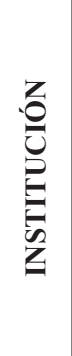 & 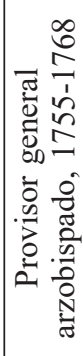 & 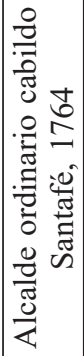 & 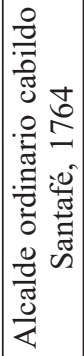 & 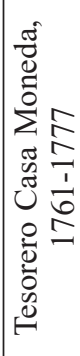 & 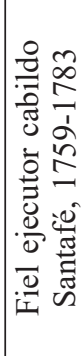 & 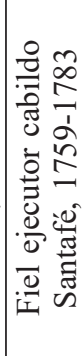 & 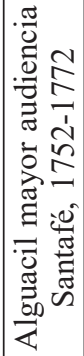 & 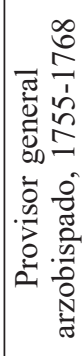 & 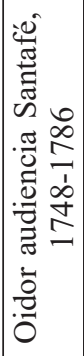 & 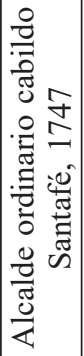 & 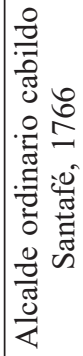 & 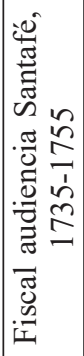 & 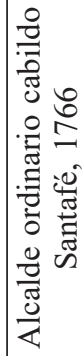 \\
\hline 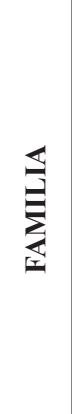 & 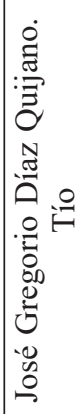 & 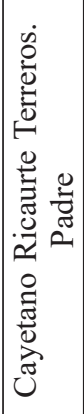 & 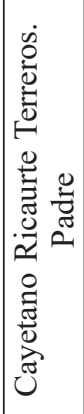 & 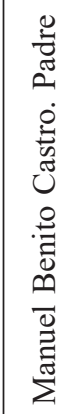 & 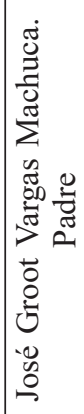 & 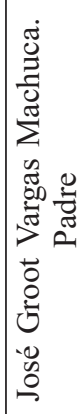 & 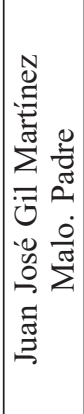 & 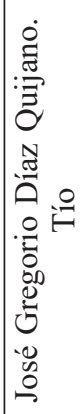 & 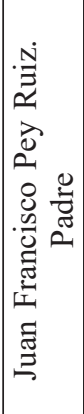 & 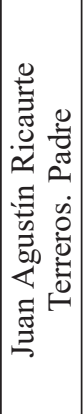 & 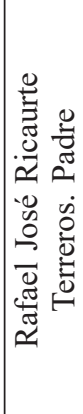 & 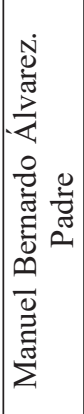 & 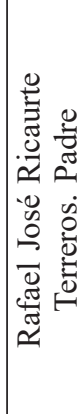 \\
\hline 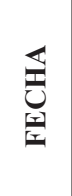 & 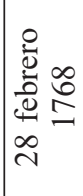 & 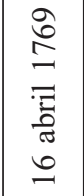 & 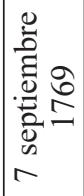 & $\stackrel{尺}{\stackrel{2}{I}}$ & 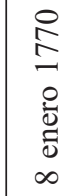 & 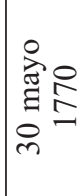 & 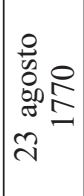 & 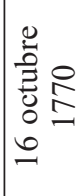 & 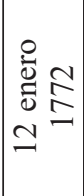 & 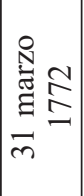 & 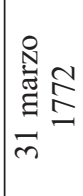 & 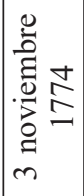 & $\begin{array}{l}\stackrel{n}{\cong} \\
\stackrel{0}{\Xi} \\
\stackrel{\Xi}{\Xi}\end{array}$ \\
\hline 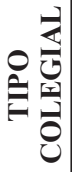 & $\begin{array}{c}\widetilde{\Xi} \\
\check{\simeq}\end{array}$ & 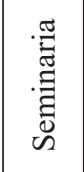 & ن̃ & $\begin{array}{l}\widetilde{\mathscr{J}} \\
\stackrel{\sim}{1}\end{array}$ & $\begin{array}{l}\overline{\mathscr{J}} \\
\approx\end{array}$ & 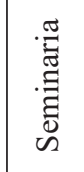 & $\begin{array}{l}\overline{\mathscr{J}} \\
\simeq\end{array}$ & $\begin{array}{l}\mathscr{Q} \\
\stackrel{0}{0} \\
\stackrel{\Xi}{\Xi}\end{array}$ & שֶّ & 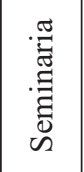 & 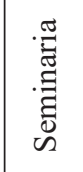 & $\underset{\mathscr{E}}{\tilde{E}}$ & $\begin{array}{l}\overline{\mathscr{J}} \\
\simeq\end{array}$ \\
\hline 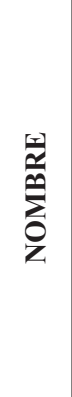 & 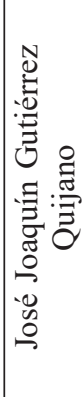 & 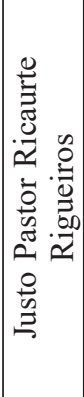 & 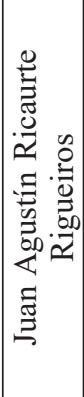 & 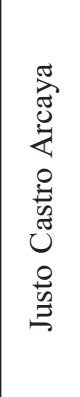 & 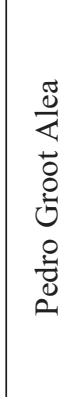 & 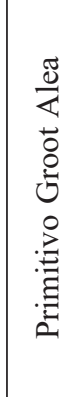 & 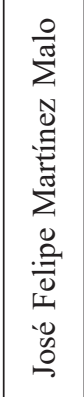 & 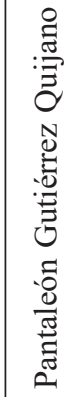 & 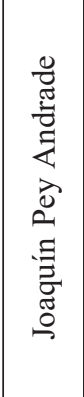 & 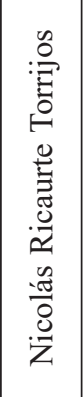 & 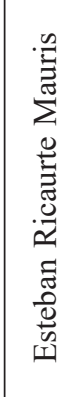 & 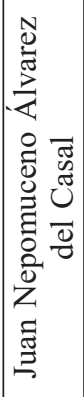 & 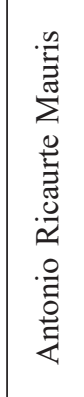 \\
\hline
\end{tabular}




\begin{tabular}{|c|c|c|c|c|c|c|c|c|c|c|}
\hline 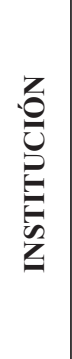 & 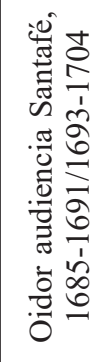 & 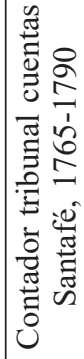 & 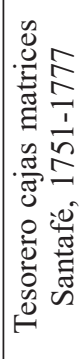 & 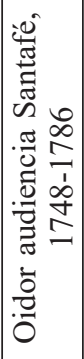 & 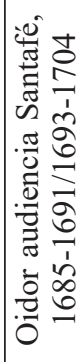 & 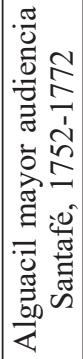 & 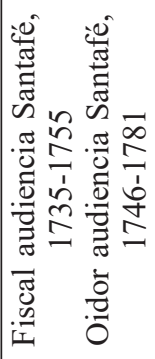 & 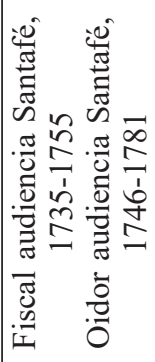 & 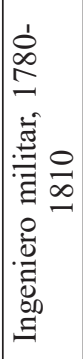 & 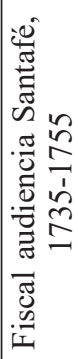 \\
\hline 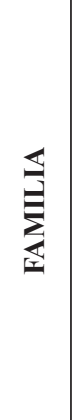 & 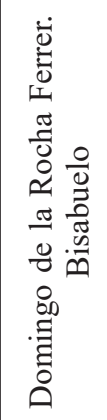 & 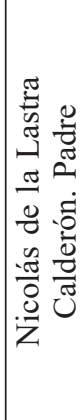 & 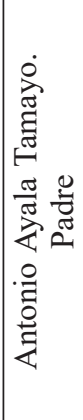 & 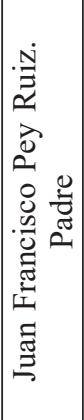 & 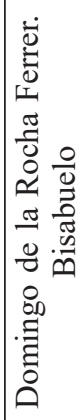 & 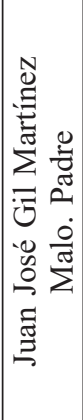 & 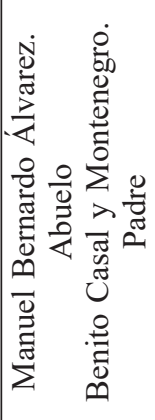 & 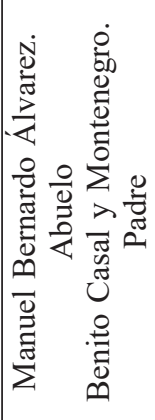 & 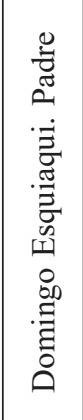 & 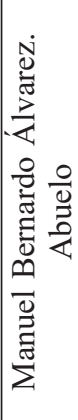 \\
\hline 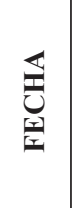 & 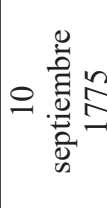 & 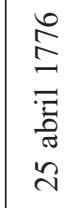 & 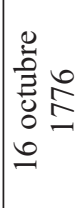 & 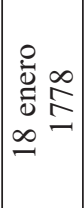 & 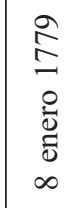 & $\begin{array}{l}\infty \\
\infty \\
= \\
\bar{\Xi} \\
0 \\
0 \\
0\end{array}$ & $\begin{array}{l}\infty \\
\infty \\
= \\
\bar{\Xi} \\
0 \\
0 \\
0\end{array}$ & 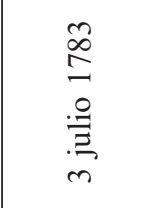 & 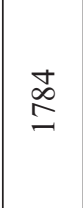 & 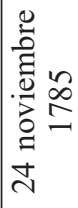 \\
\hline 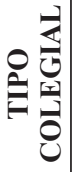 & ن & $\begin{array}{l}\overrightarrow{\mathscr{J}} \\
\widetilde{\simeq}\end{array}$ & $\begin{array}{l}\overline{\mathscr{D}} \\
\stackrel{\simeq}{*}\end{array}$ & 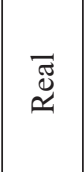 & $\begin{array}{l}\overline{\mathscr{J}} \\
\widetilde{\simeq}\end{array}$ & $\begin{array}{l}\overrightarrow{\mathscr{D}} \\
\stackrel{\sim}{*}\end{array}$ & $\begin{array}{l}\overline{\mathscr{J}} \\
\widetilde{\sim}\end{array}$ & $\begin{array}{l}\overline{\mathscr{J}} \\
\widetilde{\simeq}\end{array}$ & 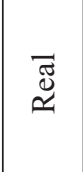 & Æֶّ \\
\hline 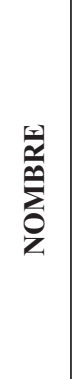 & 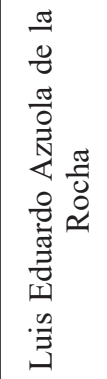 & 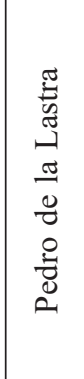 & 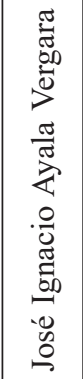 & 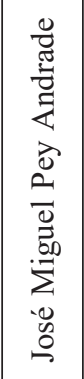 & 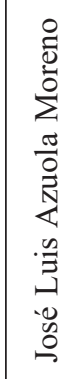 & 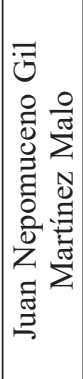 & 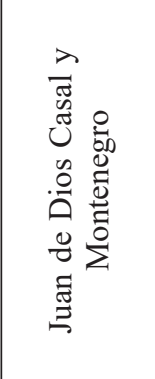 & 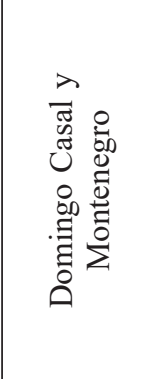 & 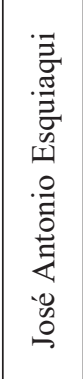 & 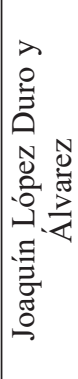 \\
\hline
\end{tabular}


do secular y eclesiástico, el tribunal de cuentas y la casa de la moneda que llenaban las renovadas aulas bartolinas vistiendo becas específicas ${ }^{38}$. Esta presencia postexpulsión nos puede llevar a concluir que la salida jesuita significó la apertura de las aulas y becas al poder institucional y secular, una realidad que, a pesar de lo que pueda aparentar, no se circunscribe al período postjesuita sino que necesariamente nos retrotrae a mediados del siglo XVII.

\section{LA AUDIENCIA DE SANTAFÉ Y LA POBREZA DEL REINO}

El 20 de febrero de 1654, el presidente y los oidores de la audiencia de Santafé hicieron llegar una solicitud al Rey en la que presentaban la necesidad de crear un "grupo de becas reales» en el Seminario de San Bartolomé. Los argumentos esgrimidos por los ministros se resumen en el siguiente párrafo:

La experiencia ha mostrado en esta ciudad el desdichado fin a que de ordinario han venido los hijos y descendientes de ministros de VM, que en ella han servido plazas de oidores, contadores de cuentas y otras de administración de justicia, siendo la causa principal la pobreza de la tierra (...) los descendientes de quien ha servido aquí no experimenta ninguno [premio] por estar distantes de la vista de VM que los premie (...) hemos hallado que hay en esta ciudad un colegio seminario (...) a cargo de los padres de la Compañía (...) ha venido a mucha disminución el Seminario con que hoy más sustentan el colegio los convictores que pagan estipendio, que los seminarios que nombra el patrono, sin que en estos entren los hijos de los ministros sino solo los de la tierra (...) y para que esto se remediase nos parece podrá darse alguna pensión en indios vacos de hasta 500 patacones para que añadiéndose cuatro becas de colegiales y que estos fuesen en primer lugar hijos de ministros, y no los habiendo descendiente de los conquistadores (...) y podrá ser el nombramiento de dichos cuatros colegiales hechos por el presidente y los dichos colegiales llamarse Reales ${ }^{39}$.

38 Nos referimos a becas específicas en tanto que a la condición de colegial se le sumaba una remuneración otorgada por una institución o particular. Así, tomar beca en un colegio hacía referencia a la «prebenda o plaza que se gozaba al ser colegial», al entrar al colegio, convirtiéndose beca en sinónimo de colegial, materializado en la prenda o «insignia de diversos colores» que distingue a los colegiales. Diccionario de Autoridades, 1726-1739. Además, en cada una de las instituciones educativas existen becas, colegiales, específicas, cuya calidad y naturaleza se relaciona con el origen de los recursos para el pago de sus estudios y sustento en la institución. Guillén de Iriarte, 1994, vol. I: 24-25. En San Bartolomé, como veremos a continuación, se dieron becas seminarias, financiadas por las rentas eclesiásticas; becas reales, financiadas por las rentas reales; y becas particulares, financiadas por familias o individuos específicos.

39 Petición de la audiencia de Santafé de aumento de cuatro becas en el Colegio de San Bartolomé, AHJJMP, FPE, B1-ES1-EN1-CP26-DVD 01, doc. 411, fs. 1r-1v. El subrayado es nuestro. 
La petición subrayaba, por un lado, la pobreza del Reino y la falta de premios y mercedes para los ministros de su majestad y, por otro, y en relación con la ausencia de descendientes de los oficiales reales en esta institución, la patrimonialización de las becas seminarias por parte de los «hijos de la tierra». Frente a esta situación de desventaja, la audiencia solicitaba que los «hijos de los ministros» fueran investidos como colegiales reales, designados por el presidente de la audiencia y mantenidos por el erario real.

Estas nuevas becas solicitadas por la audiencia se sumarían a las 14 becas seminarias instauradas en San Bartolomé desde su fundación en 1605. En las Constituciones fundacionales, Bartolomé Lobo Guerrero definió que los candidatos a vestir la beca seminaria debían ser «... pobres españoles y de legítimo matrimonio y de edad por lo menos de doce años y que sepan bien leer y escribir de buenas costumbres y habilidad, y sean preferidos con iguales partes los descendientes de los conquistadores ${ }^{40}$. Unas becas de provisión arzobispal, con una renta anual de «... 100 pesos de a 13 quilates por año para su sustento y gasto (...) de las rentas eclesiásticas» ${ }^{41}$ de este arzobispado, tal y como se había definido $-\mathrm{y}$ así los recogen las Constituciones - en el Concilio de Trento. Junto con los seminaristas, el Colegio contó, desde 1610, de colegiales convictores o porcionistas. Unos colegiales que vivían en el convictorio bartolino, no estudiaban para ser sacerdotes y pagaban, por constitución, una pensión anual de 100 pesos. Una cantidad generalmente rebajada a 60-70 pesos tras alegar una situación de nobleza empobrecida, una constante en las solicitudes de los pretendientes ${ }^{42}$.

40 Constituciones y testimonio de erección del Colegio Seminario de San Bartolomé. Capitulo 1, AHJJMP, FPE, B1-ES1-EN1-CP26-DVD 01, doc. 636, f. 3v.

41 Ibidem, f. 4 r.

42 «D. Fernando Fernández de Saavedra (...) digo que mis padres me pusieron en esta ciudad y en el colegio de San Bartolomé en que ha pagado dos años por el fin de cursar los estudios y hacerme hábil para los sagrados órdenes y respecto de que las conveniencias de dichos mis padres son escasas y mi deseo el más eficaz de adquirir las facultades mayores para que pueda lograrlo, respecto de haber vacado una beca seminaria», Nombramiento de beca seminaria a D. Fernando Fernández de Saavedra, 1748, AHJJMP, FCSB, rollo 29, caja 56, f. 36v. También el colegial porcionista Bernardo Pérez solicita la concesión de beca seminaria ya que «[sus] padres no pueden soporta la anual contribución de 70 pesos al colegio», Solicitud de concesión de beca seminaria Bernardo Pérez, 1751, AHJJMP, FCSB, rollo 29, caja 56, f. 39r. «... en este colegio se halla vistiendo la beca D. Ignacio Roel (...) persona decente, de buen genio, natural y buena crianza, en que se expresa conseguir el fin de los santo intentos del concilio tridentino y hallarse sus dichos padres faltos de medios para poderlo mantener de su consta en los estudios si fuere del beneplácito de V.S. Yllma podrá 
Por tanto, la petición de la audiencia, en caso de ser aceptada por la Corona, significaría la definición al interior del Seminario de un nuevo tipo de colegial, que materializaba la reunión, en una sola institución, de colegiales laicos - reales y convictores - que se formaban en gramática, filosofía y teología, junto a seminaristas destinados a las diferentes jerarquías eclesiásticas del reino; y todos bajo la dirección de la Compañía de Jesús.

Volviendo a la carta del tribunal, es muy interesante el momento en el que la audiencia realiza la solicitud al monarca. Dos meses antes, el 18 de diciembre de 1653, finalmente se inauguraba el Colegio Mayor Nuestra Señora del Rosario, tras casi una década de «ires y venires» en su organización y licen$\mathrm{cia}^{43}$. En las Constituciones de la nueva institución educativa se subraya que sus colegiales «han de corresponder a la nobleza secular del reino (...) por esta vez nos reservamos [Torres] a nos el nombramiento de los colegiales, por tanto que queremos que la primera fundación de este colegio sea con piedras preciosas de hombres ilustres en sangre (...) por la gran notoriedad de su nobleza» ${ }^{44}$.

La definición de la naturaleza de los colegiales que debían formarse en las recién estrenadas aulas rosaristas, respondía, aunque en una nueva institución, a lo denunciado por la audiencia, esto es, que el conjunto de las becas seminarias bartolinas y las de primera fundación rosarista compartían el mismo horizonte de elección; una preferencia por los descendientes de los conquistadores e ilustres en sangre, en otras palabras, los herederos de los beneméritos neogranadinos, de «los hijos de la tierra». Así, 14 prebendas en San Bartolomé y 15 en el Rosario, otorgadas las primeras por el arzobispo y por el presidente de la audiencia las segundas, tenían como destinatarios a los descendientes de las más notorias familias conquistadoras, creando un escenario de poder al interior de ambas instituciones, que convertía el pago de pensión en la única vía de entrada para los hijos y descendientes no beneméritos.

nombrarlo en la precita beca vacas», Nombramiento de beca seminaria a Ignacio Roel, 1754, AHJJMP, FCSB, rollo 29, caja 56, f. 46r.

43 Guillén de Iriarte, 1994, vol. I: 5-14.

44 Constituciones, Título III, Constitución II. Los colegiales de primera fundación, también llamados formales o de número, eran originalmente 15 , pero su número podía variar en virtud de la renta del colegio. Inicialmente, eran nombrados por los vicepatronos, presidentes y virreyes, que realizaban la designación de forma directa. Sin embargo, desde mediados del siglo XVIII, las becas comenzaron a asignarse por oposición o concurso. La resolución de la convocatoria se notificaba al virrey, quien la refrendaba. Guillén de Iriarte, 1994, vol. I: 22-26. El subrayado es nuestro. 
Un breve recorrido por los expedientes de los colegiales recopilados por María Clara Guillén de Iriarte en su obra Nobleza e Hidalguía, nos permite ver cómo esas «piedras preciosas» comenzaron a ingresar en la institución desde sus primeros compases. Así, fueron colegiales, entre 1657 y 1713, Francisco José y Agustín Flórez de Acuña, Pedro Tovar Vergudo, Luis Francisco Valenzuela Fajardo Beltrán de Caicedo, Pedro Jerónimo Flórez Venegas, Nicolás Santamaría Angulo, Antonio Vélez Ladrón de Guevara y Caicedo, Juan Agustín Vergara Azcárate Dávila y Sandoval y Francisco Tovar y Guzmán entre otros. Todos ellos descendientes de las primeras familias de este Reino, cuyos linajes conformaron, en 1672, el sustento de la labor nobiliario-genealógica de Juan Flórez de Ocáriz ${ }^{45}$.

Para el caso bartolino, desgraciadamente, no contamos con expedientes anteriores a $1689^{46}$, no obstante, como hemos visto, la definición de las calidades del colegial seminarista, el de primera fundación bartolina, ponía negro sobre blanco la «preferencia en iguales partes» por los descendientes de los conquistadores, por la nobleza secular neogranadina ${ }^{47}$.

Volviendo a la petición de la audiencia, en el año de 1660 se presenta un informe del Consejo de Indias sobre la posibilidad de conceder la gracia solicitada, ya que «con esto no se altera en nada la primera erección ni el patronato del arzobispo» ${ }^{48}$, y se solicita la opinión del arzobispo santafereño y de su cabildo, en tanto patronos del Seminario, en torno a la petición del tribunal de redefinir el corpus estudiantil de la institución pedagógica conciliar. Este mismo año, los miembros del gobierno eclesiástico dieron su aval a la solicitud de la audiencia, justificando éste, curiosamente, con los mismos argumentos esgrimidos por el tribunal: la pobreza de la tierra y el hecho de que el grueso de las becas seminarias y porcionistas «eran para los naturales del reino», circunstancia que impedía a los ministros «responder a las exigen-

45 En 1674, Juan Flórez de Ocáriz, escribano del cabildo santafereño, finalizó el proyecto capitular de recopilación de la filiación y parentesco de las principales familias de la capital, con el objetivo de rastrear su origen hasta los «primeros conquistadores y pobladores de estas repúblicas», definiendo una suerte de censo y condición del ser de la nobleza neogranadina. Flórez de Ocáriz, 1674 [1990].

46 Del conjunto de los autores que trabajan el Seminario bartolino solo Jaramillo Mejía, 1996, se detiene a analizar el contenido de las informaciones de legitimidad y limpieza presentadas por los pretendientes a colegiales, de hecho, él es el único que señala la fecha de los primeros expedientes. Sin embargo, no se cuestiona en ningún momento el vacío documental existente entre 1605 y 1689.

47 Constituciones y testimonio de erección del Colegio Seminario de San Bartolomé. Capitulo 1, AHJJMP, FPE, B1-ES1-EN1-CP26-DVD 01, doc. 636, f. 3v.

48 Petición de la audiencia de Santafé de aumento de cuatro becas en el Colegio de San Bartolomé, AHJJMP, FPE, B1-ES1-EN1-CP26-DVD 01, doc. 411, f. 6v. 
cias de su cargo» ${ }^{49}$. Una respuesta que allanaba el camino a la pretensión de los ministros.

\section{Los Colegiales Reales}

Una década después de la petición de la audiencia, se promulga, el 26 de marzo de 1664, la real cédula por la que se establecen 4 becas reales en San Bartolomé. La primera parte de la cédula recoge los argumentos y las propuestas realizadas por la audiencia una década atrás:

... mi real audiencia me dio cuenta en carta de 20 de febrero del año 1654 del desamparo con que quedaban de ordinario los hijos y descendientes de los ministros que me habían servido en plazas de oidores y de contadores de cuentas y otros de administración de justicia así por la pobreza de la misma tierra como por no tener en ella premio señalado como en otras partes, proponiendo para remedio (...) que se aumentasen cuatro beca de colegiales en el seminario (...) a cargo de los padres de la compañía (...) y que estos fuesen en primer lugar hijos de ministros míos y no los habiendo descendientes de conquistadores (...) que el nombramiento de los dichos cuatro colegiales se hiciese por el presidente de esa Audiencia llamándose colegiales reales ${ }^{50}$.

Por lo tanto, el monarca subraya, por un lado, el desamparo y la pobreza a la que se ven abocados tanto por las condiciones de la propia tierra como por no recibir ningún premio y, por otro, y como consecuencia de lo anterior, la condición de que las nuevas becas tuvieran como destinatarios preferentes a sus hijos, con el objetivo de revertir la realidad reinante en San Bartolomé y en el recién fundado Rosario. Así, el monarca deja constancia de su resolución:

He resuelto que en el Colegio de esa ciudad se acrecienten las cuatro becas que me propuso [la audiencia] y que estas sean a provisión de mi presidente y haya de nombrar en ella a los hijos y descendientes legitimos de todos los ministros de esa audiencia y del fiscal de ella así mismo los que fueren de los contadores de

49 Real Cédula al arzobispo de la Iglesia Metropolitana de Santafé o al Deán y Cabildo de ella para que informen sobre lo que ha propuesto la Real Audiencia de Santafé acerca de aumentar cuatro becas en el Colegio Seminario, que está a cargo de la Compañía de Jesús, Madrid, 31 de marzo de 1660, AHJJMP, FPE, B1-ES1-EN1-CP26-DVD 01, doc. 448, fs. 1r y $1 \mathrm{v}$.

50 Real Cédula al presidente de la audiencia sobre el aumento de cuatro becas en el Colegio Seminario de San Bartolomé, Madrid, 26 de marzo de 1664, AHJJMP, FPE, B1-ES1EN1-CP26-DVD 01, doc. 855, f. 283r. El subrayado es nuestro. 
cuentas y a falta de estos los hijos y descendientes de los oficiales de mi real hacienda y de gobernadores y capitanes, que se hayan ocupado en mi servicio y que para el sustento de estos cuatro colegiales (...) pensiones de encomiendas (...) 500 pesos de renta cada año ${ }^{51}$.

El análisis del contenido de la real cédula nos muestra una reseñable jerarquía en la relación de candidatos a las becas. Así, se presentan como primeros los descendientes de los ministros y fiscales de la audiencia, institución que encabeza la petición, los hijos de los contadores de cuentas son los segundos, seguidos por los oficiales de la real hacienda y, cuartos y últimos, los de gobernadores y capitanes. Esto es, y como lo solicitaban los ministros, las becas se convierten en el premio para aquellos que se hayan ocupado en el servicio al rey, un premio por los servicios prestados; «... aún cuando esa semejante gracia hallando anteriormente concedida a algún otro respecto a que la Real Fundación de semejantes becas deben ser preferidos en ellas los hijos de ministros a cualquier otro interesado» ${ }^{52}$, recuerda y remarca el oidor Juan Francisco Pey Ruiz un siglo después de la real cédula.

Por lo tanto, el establecimiento de los colegiales reales no solo marca el ingreso de la autoridad real en el marco de la toma de decisiones del colegio, ya que es el presidente, y posteriormente el virrey, quien designa a estos nuevos miembros, sino que teje nuevos vínculos entre San Bartolomé y los resortes del poder institucional, cuyos hijos comienzan a formarse en el colegio con sus becas específicas, comenzando un período en el cada vez más «hijos de las instituciones» comparten aulas con «hijos de la tierra».

Una redefinición del corpus colegial de San Bartolomé, introduciendo un nuevo perfil de colegial nombrado y mantenido por la Corona, que responde a la exigencia de los propios «burócratas de $\mathrm{Su}$ Majestad» ${ }^{53}$, quiénes, en su petición, se apropian y moldean a su favor, con el fin de defender sus prerrogativas, las estrategias discursivas de los conquistadores y sus herederos. Desde mediados del siglo XVI, los conquistadores neogranadinos comenzaron a acudir al Consejo de Indias a quejarse «amargamente por no haber sido recompensados conforme a la "calidad" de su persona y a la magnitud de los servicios realizados (...) sufriendo mil privaciones (...) hasta quedar en la

51 Real Cédula al presidente de la audiencia sobre el aumento de cuatro becas en el Colegio Seminario de San Bartolomé, Madrid, 26 de marzo de 1664, AHJJMP, FPE, B1-ES1EN1-CP26-DVD 01, doc. 855, f. 283v. El subrayado es nuestro.

52 Concesión de beca real a Joaquín Pey Andrade, AHJJMP, FCSB, rollo 30, caja 58, f. $198 \mathrm{v}$.

53 Ramos Peñuela, 2009: 24. 
más absoluta pobreza» ${ }^{54}$. Unos argumentos que, aproximadamente un siglo después, harán suyos los ministros y oficiales reales santafereños, quienes enarbolando la bandera del servicio prestado al rey y del injusto desposeimiento de lo que les es merecido, hacen que la lógica del gobierno justo y el leal y heroico vasallo en el ejercicio y servicio al rey trascienda el tradicional escenario benemérito, ampliando el espectro de insatisfacción por las mercedes y privilegios recibidos.

Así, desde un reformulado argumentario conquistador-benemérito la Corona propicia la consolidación de un nuevo escenario de poder en el seno de la institución bartolina. Las nuevas becas a hijos y descendientes de ministros y oficiales reales materializan la intromisión de la autoridad real en San Bartolomé, redireccionando, además, el favoritismo regio hacia sus empleados, de la mano de unos premios en los que tanto cuantitativo como cualitativamente se subraya la preeminencia de los agentes coloniales ${ }^{55}$.

En este sentido, es significativo el hecho de que a partir de la creación de las becas reales la institución bartolina comenzó a denominarse Real Colegio y Seminario de San Bartolomé, tanto así que en el Catálogo de la Provincia del Nuevo Reino del año 1671 se oficializó esta denominación. Una posibilidad de redenominación que fue rechazada por la Corona en 1689, que distinguió claramente entre las becas creadas, que eran las que debían denominarse como reales, y el grueso de la institución. Por tanto, en virtud de lo expuesto por la Corona eran los colegiales los que disfrutaban de la prerrogativa de lo real, como «premio» a la labor y servicios prestados por sus progenitores, mientras que el Colegio se mantenía en su condición originaria $^{56}$. Sin embargo, a pesar de esta negativa de la Corona, San Bartolomé siguió denominándose de facto como Colegio Real y Seminario, subrayando las dos realidades existentes al interior del mismo ${ }^{57}$.

Es remarcable el hecho de que, ante esta nueva realidad en la concesión de becas, ni las familias beneméritas ni el arzobispo se hubieran opuesto a estas redefinidas preeminencias. Una tranquilidad que se puede vincular con el hecho de que los contornos de designación de los colegiales seminarios en

\footnotetext{
54 Gamboa Mendoza, 2002: 23.

55 Recordemos que, aunque eran tan solo 4 becas reales, cada una de ellas superaba en 25 pesos a las seminarias destinadas a los descendientes de los conquistadores.

56 Salazar, 1946: 353

57 La Real cédula del 25 de noviembre de 1704 resolvió «que los dos colegios de N. S. Del Rosario y San Bartolomé gocen recíprocamente el uno de los privilegios del otro, y el otro de los del otro» y significó un nuevo cambio en la denominación de San Bartolomé, que pasó a ser Real Colegio Mayor y Seminario; espejo de la titulación rosarista. Pacheco, 1959, vol. III: 121.
} 
San Bartolomé y los de primera fundación en el Rosario no se modificaron, seguían señalando las «limpias y preciosas piedras». Unas condiciones que, en el Rosario, no se modificaron a pesar de la salida de los dominicos de la institución y de la asunción total del patronato por parte de la Corona en marzo de $1665^{58}$. Esta nueva coyuntura definía una interesante dualidad, las nuevas becas bartolinas, las reales, y las viejas becas rosaristas, las de primera fundación, eran designadas por el presidente y sostenidas por la real hacienda. Unas similitudes que terminaban tanto en la naturaleza y cuantía de los nominados, cuatro hijos de ministros versus 15 «piedras preciosas», así como en la remuneración de las mismas, 500 pesos de oro para 4 becas y 500 ducados para 15 .

A continuación, presentamos la tabla 2 con un ejercicio de conversión y comparación de las cantidades de cada una de las becas; para el mismo nos hemos servido de las herramientas de cambio y conversión presentadas por Jorge Gamboa en su texto El precio de un marido, así como por la definición y correspondencias que recoge el Diccionario de autoridades ${ }^{59}$.

Por tanto, entendiendo que las becas reales y las de primera fundación rosarista se corresponderían con una moneda de quilataje equivalente, la seleccionada en la siguiente tabla, se evidencia que la pensión anual de cada uno de los colegiales reales de San Bartolomé no solo era más alta que la de sus compañeros seminarios bartolinos sino también que la de los colegiales formales rosaristas. Por lo tanto, a pesar de que el número de becas era menor, o precisamente por eso, el rey premiaba a cada uno de los becados, y a sus familias, con una asignación más alta.

Esta realidad va a transformarse a principios del siglo XVII. Aunque no podemos especificar la fecha exacta del cambio, contamos con un documento que señala que, en 1716, las becas reales en San Bartolomé eran 6 en lugar de $4^{60}$. Fueron los propios ministros de la audiencia los que propiciaron y defendieron este aumento, argumentando que los 500 pesos eran mucha renta para 4 colegiales y, sobre todo, que eran mucho los descendientes de mi-

58 Tras un largo y complicado pleito de 10 años y con la institución en ruina económica, los dominicos entregaron el Colegio, que siguió en marcha bajo la dirección del patronato regio. Guillén de Iriarte, 1994, vol. I: 15-19.

59 Gamboa Mendoza, 2003: 214. Diccionario de Autoridades, Tomo III, 1732, Ducado, http://web.frl.es/DA.html.

${ }^{60}$ Real Cédula dirigida a la Real Audiencia de Santafé aclarándole lo que ha de ejecutar sobre la instancia de la Compañia de Jesús de aquella provincia para que dos de las becas del colegio de San Bartolomé sean de cánones y leyes, Buen Retiro, 6 de septiembre de 1716, AHJJMP, FPE, B1-ES1-EN1-CP26-DVD 01, doc. 973, f. 1r. 


\section{TABLA 2: CONVERSIÓN CUANTÍA BECAS REALES BARTOLINAS Y ROSARISTAS DE PRIMERA FUNDACIÓN}

\begin{tabular}{|c|c|c|c|c|}
\hline \multicolumn{5}{|c|}{ Conversión Gamboa. Pesos fines XVI y principios XVII } \\
\hline 1 peso oro 22,5 quilates & $\begin{array}{c}589 \\
\text { maravedís }\end{array}$ & $\begin{array}{c}500 \text { pesos }= \\
294.000 \text { mrvs. }\end{array}$ & 14 & $\begin{array}{l}73.500 \text { mrvs. } \\
\text { Año/beca }\end{array}$ \\
\hline 1 peso oro 20 quilates & $\begin{array}{c}523 \\
\text { maravedís }\end{array}$ & $\begin{array}{c}500 \text { pesos }= \\
261.500 \text { mrvs. }\end{array}$ & $/ 4$ & $\begin{array}{c}54.125 \text { mrvs. } \\
\text { Año/beca }\end{array}$ \\
\hline 1 peso oro 16 quilates & $\begin{array}{c}418 \\
\text { maravedís }\end{array}$ & $\begin{array}{c}500 \text { pesos }= \\
209.000 \text { mrvs. }\end{array}$ & $/ 4$ & $\begin{array}{l}52.250 \mathrm{mrvs} . \\
\text { Año/beca }\end{array}$ \\
\hline \multicolumn{5}{|c|}{ Conversión Diccionario de Autoridades. Ducados } \\
\hline $\begin{array}{l}\text { Reyes Católicos, } 1 \text { ducado } \\
\text { oro } 23 \text { quilates }\end{array}$ & $\begin{array}{c}375 \\
\text { maravedís }\end{array}$ & & & \\
\hline $\begin{array}{l}\text { Carlos I, } 1 \text { ducado } \\
\text { oro } 23 \text { quilates }\end{array}$ & $\begin{array}{c}429 \\
\text { maravedís }\end{array}$ & & & \\
\hline $\begin{array}{l}\text { Desde Felipe II } 1 \text { ducado } \\
\text { oro } 23 \text { quilates }\end{array}$ & $\begin{array}{c}1.372 \\
\text { maravedís }\end{array}$ & $\begin{array}{l}500 \text { dcds. }= \\
686.000 \text { mrvs. }\end{array}$ & $/ 15$ & $\begin{array}{l}45.733 \text { mrvs. } \\
\text { Año/beca }\end{array}$ \\
\hline
\end{tabular}

nistros «pobres», por lo que era necesario aumentar el número de becas a 6 , lo que supondría que cada colegial recibiría una pensión de 83 pesos anuales.

... habiendo SM consignado quinientos pesos para cuatro becas dotándolas a ciento y veinte y cinco [sic] pesos cada una les pareció a los señores de la real audiencia y su presidente que era mucha renta para cuatro colegiales; y así determinaron se sustentasen en seis colegiales, a ochenta y tres pesos cada uno, y el colegio consintió en ellos por haber mucho descendientes de ministro pobres y por dar gusto a los señores y así se han mantenido siempre seis colegiales reales con los quinientos pesos a razón de ochenta y tres pesos cada uno ${ }^{61}$.

Esta cantidad, a pesar de la reducción, y siguiendo con la conversión anterior, seguía siendo superior a la que recibían los colegiales rosaristas - 49.000 maravedías por año para cada colegial bartolino frente a los 45.733 rosaristas $^{62}$ - , por lo que seguía respondiendo a esa remarcada preferencia.

61 Testimonio de la representación hecha en el superior gobierno del Nuevo Reino de Granada por parte del Colegio Real Mayor y Seminario de San Bartolomé sobre la satisfacción de lo que se le está debiendo de las rentas asignadas para becas reales y seminarias de dicho colegio, Santafé 4 de mayo de 1751, AHJJMP, FPE, B1-ES1-EN1-CP26-DVD 01, doc. 1251, f. $2 \mathrm{v}$.

62 Conversión pesos: 1 peso de oro de 22,5 quilates $=589$ maravedís. 500 pesos $=294.000$ maravedís. 6 becas $=49.000$ maravedís año/beca. 
En este sentido, la Corona, nuevamente, aceptaba el sentir y la gestión de la audiencia en pro del aumento y fortalecimiento de los escenarios de formación de «sus hijos».

Retomemos la Real cédula de 1664 y fijémonos de nuevo en la relación de la candidatos a las becas reales. Así, los hijos de los ministros y fiscales de la audiencia eran los primeros candidatos, seguidos por los hijos de los contadores de cuentas y, a la falta de éstos, los hijos de los de los oficiales de la Real hacienda y de gobernadores y capitanes. Desde esta relación institucional, analicemos las becas reales concedidas desde finales del siglo XVII hasta finales del siglo XVIII en cada institución.

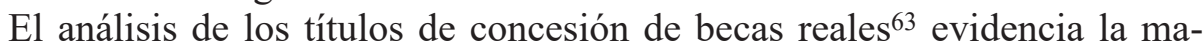
terialización en San Bartolomé del «premio» solicitado por la real audiencia. Desde el momento de la promulgación de la real cédula, y más con el aumento del número de becas, encontramos una presencia constante de la institucionalidad en San Bartolomé, representada en sus hijos, muchos de los cuales serán, además, los herederos no solo de este poder institucional sino de los vínculos establecidos entre ambos escenarios de poder, ya que los hijos de éstos, los nietos de los primeros, serán, de nuevo, candidatos a estas becas para hijos y descendientes de los ministros del rey ${ }^{64}$. Esta presencia de lo institucional contará, además, con la vertiente de lo familiar, ya que de la mano tanto de la múltiple concesión de becas a descendientes de la una misma familia como del hecho de que una beca se podía ceder a un hermano, una vez finalizados los estudios por parte del becario o por otra circunstancia, con la autorización del patrono de la misma beca ${ }^{65}$, las familias van a tener múltiples posibilidades de actuación al interior de la institución bartolina.

63 Los títulos de concesión de becas reales bartolinas se localizan en el rollo 30 del Fondo Colegio de San Bartolomé del Archivo Histórico Javeriano Juan Manuel Pacheco S. J.

64 El ANEXo I contiene las tablas con la relación de becas concedidas a hijos y descendientes del organigrama institucional neogranadino desde fines del siglo XVII a principios del XIX. Para un análisis de estas dinastías institucionales en la Nueva Granada véase Marín Leoz, 2008 y Vázquez Varela, 2010.

65 Ignacio Salazar Porras hace «desistimiento» de su beca seminaria en su hermano menor Pablo, ya que el primero estaba a punto de finalizar sus estudios mayores en la facultad de derecho canónico. Nombramiento de beca seminaria a Pablo Salazar Porras, 1751, AHJJMP, FCSB, rollo 29, caja 56, fs. 41r-42v. El oidor de la audiencia, Juan Francisco Pey Ruiz, solicita que la beca real que disfrutaba su hijo Juan Bautista, pase a su hijo José Miguel, ya que el primero había finalizado sus estudios. José Miguel obtiene la beca el 22 de enero de 1778 . Nombramiento de beca Real a José Miguel Pey Andrade, Santafé, 22 de enero de 1778, AHJJMP, FCSB, rollo 30, f. 144r. El oidor Domingo Casal y Montegro solicita que tras el fallecimiento de su hijo Juan de Dios, la beca que este disfrutaba se le conceda a su hijo Domin- 
Esta presencia familiar no se va a relacionar únicamente con las becas reales, aunque si que la relación con estas prebendas va a ser mayoritaria, sino que en la misma familia se van sumando diferentes tipos de becas, cuyo origen, cuantía, naturaleza y condición se presenta en la tabla 3. Una multiplicidad de becas que concretan un escenario de concesión múltiple en cuanto a patronos y cuantías, que hace que la confluencia de becas seminarias, reales, convictoras, Quiñones y Lozano en una misma familia, amplie la influencia y relevancia de los agentes administrativos coloniales al interior del devenir bartolino. En este sentido, hay que subrayar que el horizonte de selección del grueso de las becas se circunscribía a aquellos que atestiguaban su legitimidad y limpieza ${ }^{66}$.

El examen de estas «pluriconcesiones» familiares, cuyo desgrane institucional, familiar y cronológico se observa en las tablas del Anexo II, nos permite mostrar una serie de realidades significativas en la relación entre el Colegio Seminario y los órganos administrativos. Comenzando por el tribunal de justicia, órgano peticionario de la creación de las becas reales, sobresale la relevante relación entre cuatro de «sus familias» y San Bartolomé. Así, la del oidor Domingo de la Rocha Ferrer, con tres generaciones de descendientes formados en San Bartolomé y, en su gran mayoría, como colegiales reales. Del mismo modo, los hijos y nietos del fiscal Manuel Bernardo Álvarez — dos de ellos, a su vez, hijos del oidor Benito Casal y Montenegro-, ingresaron a San Bartolomé vistiendo, en su totalidad, becas reales. Por su parte, la presencia de la familia del oidor Juan Francisco Pey Ruiz se inicia, en 1755, de la mano de su cuñado Manuel Andrade, momento en el que oidor ya se encontraba ejerciendo en la audiencia, y continúa con sus cuatro hijos, que disfrutarán becas seminarias, reales y de Quiñones y que, durante algún tiempo, convivirán juntos como colegiales bartolinos. Por último, la familia del alguacil mayor Juan José Gil Martínez Malo de la mano de sus hijos y nietos. Una herencia en la que destaca la beca real disfrutada por José Felipe Gil Martínez Malo en 1770, como hijo del alguacil mayor de la audiencia, condición y beca que disfrutarán sus hijos, cuando, a finales del XVIII, sean becarios reales como hijos del alguacil mayor de la audiencia, José Felipe Gil Martínez Malo, empleo que heredó de su padre.

En la Casa de la Moneda, por su parte, sobresale la presencia continua de los hijos del contador oficial Manuel Benito Castro, quienes, durante el tiem-

go. Nombramiento de beca Real a Domingo Casal y Montenegro, Santafé, 3 de julio de 1783, AHJJMP, FCSB, rollo 30, f. 236r.

66 Sobre el proceso de selección de los colegiales de San Bartolomé y las informaciones de legitimidad y limpieza véase Marín Leoz, 2015. 


\section{Tabla 3: Tipología becas y Colegiales Colegio Seminario SAN BARTOLOMÉ EN 1767*}

\begin{tabular}{|c|c|}
\hline $\begin{array}{c}\text { 14 BECAS SEMINARIAS } \\
\text { Fundadas en } 1605 \\
\text { Provisión y patronato arzobispas } \\
\text { Renta anual } 100 \text { pesos en rentas del arzobispado } \\
\text { Españoles pobres y descendientes de los } \\
\text { conquistadores } \\
\text { Formación sacerdotal } \\
\text { Expediente de legitimidad y limpieza }\end{array}$ & $\begin{array}{c}\text { 30-35 CONVICTORES } \\
\text { Fundadas en } 1610 \\
\text { Provisión Rector San Bartolomé } \\
\text { Pago de pensión anual de } 60-70 \text { pesos } \\
\text { Formación secular } \\
\text { Expediente de legitimidad y limpieza }\end{array}$ \\
\hline $\begin{array}{c}\text { 6 BECAS REALES } \\
\text { Fundadas } 3 \text { en } 1664 \\
\text { Aumento a } 6 \text { c. } 1700 \\
\text { Provisión presidente audiencia-patronato real } \\
500 \text { pesos oro anuales en pensiones de } \\
\text { encomiendas reales } \\
\text { Hijos y descendientes de ministros y oficiales } \\
\text { reales } \\
\text { Formación secular } \\
\text { Expediente de legitimidad y limpieza }\end{array}$ & $\begin{array}{c}2 \text { BECAS ARZOBISPO LOZANO } \\
\text { Fundadas en } 1688 \\
\text { Nominación cabildo Cartagena y designación } \\
\text { del arzobispo de Santafé } \\
\text { Patrimoniales ilustres de Cartagena } \\
\text { Formación secular } \\
\text { Expediente de legitimidad y limpieza }\end{array}$ \\
\hline $\begin{array}{c}1 \text { BECA DEAN JUAN BAUTISTA MARTÍNEZ } \\
\text { OVIEDO } \\
\text { Fundadas c. } 1690 \\
\text { Patronato rector San Bartolomé } \\
\text { Patrimoniales pobres de Ibagué } \\
\text { Renta de } 2.000 \text { pesos } \\
\text { Formación secular } \\
\text { Expediente de limpieza y legitimidad }\end{array}$ & $\begin{array}{c}2 \text { BECAS FAMILIA SALAZAR } \\
\text { Fundadas c. } 1700 \text { por Agustín Salazar en } \\
\text { Antioquia } \\
\text { Patronato particular-familiar } \\
\text { Descendientes familia Salazar } \\
\text { Formación Secular } \\
\text { Expediente de legitimidad y limpieza }\end{array}$ \\
\hline $\begin{array}{c}4 \text { BECAS ARZOBISPO ÁLVAREZ QUIÑONES } \\
\text { Fundadas en } 1736 \\
\text { Provisión y patronato arzobispo de Santafé } \\
\text { Patrimoniales arzobispado de Santafé } \\
\text { Renta } 6.000 \text { pesos } \\
\text { Formación secular } \\
\text { Expediente de legitimidad y nobleza }\end{array}$ & \\
\hline
\end{tabular}

* Para la confección de la tabla se han utilizado las siguientes fuentes: Colegio de San Bartolomé, provisión de becas, oposición a ellas, nombre de los opositores y beneficios, Archivo General de la Nación, Bogotá (AGN), Fondo Colegios, leg. 2, fs. 432v, 447v, 448r-v y 453r. Testamento del arzobispo Antonio Claudio Álvarez Quiñones, otorgado por el oidor d. José de Quintana, Santafé, 27 de octubre de 1736, AGN, Notaría 1, leg. 149, Notario José Gómez Abreu, años 1736-1738, f. 59v. Carta del alumno Miguel de Riaza Saldarriaga al rector del Colegio Mayor de San Bartolomé para la integración a éste, 1757, AHJJMP, FCSB, rollo 4, caja 7, n. ${ }^{\circ}$ 683, fs. 224-231. Informe audiencia sobre patronato becas Sanz Lozano, 25 de febrero de 1697, AHJJMP, FPE, B1-ES1-EN1-CP26-DVD 01, doc. 796. Groot, 1869, vol. I: 436. Pacheco, 1959: 130. Restrepo Posada, 1961: 160. 
po de ejercicio de su padre entre 1761 y 1777, disfrutaron becas reales, de Quiñones y convictoras. En cuanto al cabildo, el protagonismo de la familia del fiel ejecutor José Groot Vargas Machuca en San Bartolomé, al igual que ocurría en la de Pey, se relaciona con el enlace matrimonial del empleado real, esto es, su vinculación con los Alea. Así, de la mano de los tíos de su mujer se inicia, a finales del XVII, la presencia de la familia en San Bartolomé; una presencia que continuará con los sobrinos nietos de estos, los hijos del fiel ejecutor, a partir de los años 60 del siglo XVIII, como seminarios, convictores y reales.

Complementando la perspectiva institucional, destacamos la presencia de una suerte de «dinastías bartolinas», que abarcan diferentes escenarios administrativos y que acompañan al Colegio Seminario durante buena parte del siglo XVIII. En primer lugar, los Ricaurte, quienes desde fines del siglo XVII $\mathrm{y}$ por diferentes generaciones, con la primera beca real concedida a un miembro de la familia - Clemente Terreros Villarreal- hasta 1790 con la beca real a José Rubio Ricaurte, fueron formados en San Bartolomé sin que la expulsión de la Compañía incidiera en su presencia. En segundo, los Quijano. En 1731, el futuro provisor del arzobispado, Gregorio Díaz Quijano, inicia como seminarista la presencia familiar, que continuarán tanto sus sobrinos, en la década de los 70, como su sobrino nieto, José Gregorio Gutiérrez Moreno, a finales del siglo XVIII. Este, además, era nieto de otro de los participantes en la madrugada de la expulsión jesuita, el también bartolino Francisco Antonio Moreno y Escandón ${ }^{67}$.

Por lo tanto, la presencia mayoritaria de los hijos y descendientes de ministros y oficiales reales no es una realidad que cristaliza después de la expulsión, fruto de una secularización de facto del Colegio Seminario y de las reformas educativa e institucionales que se sucedieron, sino que responde a una suerte de patrimonialización San Bartolomé por parte de las autoridades reales desde la fecha de promulgación de la real cédula de 1664, materializando una presencia constante y múltiple de estas «familias institucionales» entre fines del siglo XVII y todo el siglo XVIII. Así, la conversión del Colegio Seminario en escenario de formación de los hijos de los ministros, que «deben de ser preferidos» a cualquier otro, como lo subrayaba el oidor Pey, formaliza esta convivencia y «gestión» conjunta de la institución. Por tanto, el monarca, desde el momento en que premia sus ministros, pasados, presentes y futuros, como recompensa a su labor, y con el objetivo de desagraviarlos frente a los privilegios y beneficios que seguían disfrutando los herederos de los conquistadores en la Nueva Granada, hace de San Bartolomé el esce-

67 Véase ANeXo II. 
nario específico para la formación de sus descendientes, subrayando la apuesta de consolidación del orden colonial tanto en la generación que ejerce el poder en ese momento como en sus generaciones descendientes. Frente a esto, y también de la mano de la Corona, el Rosario será la institución benemérita por excelencia, reducto de fortaleza de la «primera sangre de este Reino» ${ }^{68} \mathrm{y}$ «caja fuerte» de sus piedras preciosas. Esta dualidad de condición y elección se ejemplifica con el devenir colegial de una de las más significativas familias santafereñas: los Lozano de Peralta.

Recién llegado a la capital, el oidor Jorge Lozano de Peralta solicita, en 1722, una beca real bartolina para su hijo José Antonio que, ese mismo año, había ingresado como convictor en el Colegio Seminario. Finalmente, en 1730, a José Antonio se le concede la beca real, convirtiéndose en el primer, y último, Lozano de Peralta que se formó en San Bartolomé69. El matrimonio de José Antonio con María Josefa Caicedo Villasis vincula a los Lozano de Peralta con una de las familias más representativas del ser benemérito neogranadino; heredera y guardiana de la nobleza y limpieza de la primera sangre del reino. Así, tras este entronque, los Lozano de Peralta se integran al imaginario y al ser y quehacer benemérito, por lo que todos sus sucesores y descendientes serán, cual piedras preciosas, colegiales rosaristas. Jorge Lozano y Caicedo, nieto del oidor, será colegial en 1742 - ya fallecido el abuelosus bisnietos José María y Jorge Tadeo Lozano de Peralta Manrique lo serán en la década de los 80 y sus tataranietos Federico y Rafael Lozano de Peralta vestirán beca rosarista a principios del siglo XIX ${ }^{70}$. Así, la conversión de los Lozano de hijos de las instituciones a hijos de la tierra concreta y refrenda el deber ser de cada una de las instituciones educativas.

\section{CONCLUSIONES}

La pregunta por la expulsión de la Compañía de Jesús y la continuidad del Colegio Seminario de San Bartolomé nos lleva necesariamente a analizar la tipología de los colegiales formados en sus aulas y a tratar de definir la razón de ser de su estructura y naturaleza. Este análisis nos acerca a la figura de los colegiales reales creados en 1664 como concesión real a una petición de una audiencia que se sentía agraviada por su situación de precariedad y

68 Vázquez Varela, 2010.

69 Nombramiento de beca real a José Antonio Lozano de Peralta, 1730, AHJJMP, FCSB, rollo 30 , f. 181v.

70 Guillén de Iriarte, 1994, vol I: 280 y vol. II: 480, 747 y 748. 
pobreza, en relación a sus pares en ejercicio en otros territorios americanos $\mathrm{y}$, sobre todo, en relación a las élites beneméritas neogranadinas.

Por tanto, la década de los 60 del siglo XVII materializa un escenario educativo en el que se conjugan tradición y novedad de la mano de la definición de nuevos perfiles de colegiales. Así, mientras el Colegio Real del Rosario formará a los ilustres en sangre, herederos de la nobleza benemérita, en San Bartolomé se concreta un espacio de preferencia por los hijos y descendientes de los ministros y oficiales de Su Majestad. Este nuevo perfil de colegial real respondía a la consolidación de un nuevo poder en el territorio neogranadino, el poder de los agentes del orden colonial ${ }^{71}$. Un nuevo poder que convive, y se vincula, con el benemérito, compartiendo escenarios de acción, herramientas fácticas y haciendo parte, incluso, de las mismas familias por vía matrimonial. Una dualidad entre tradición y novedad, entre conquista y colonia, que encuentra en las instituciones educativas un escenario en el que ser preferente. El Rosario "prefiriendo» a los ilustres en sangre y San Bartolomé, desde la instauración de las becas reales, «prefiriendo» a los ilustres en empleo y servicio al Rey. Ambas preferencias, además, refrendadas y garantizadas por la Corona. Una dualidad que respondía a las diferentes características definitorias de las élites rectoras neogranadinas; el Rosario resultado y garante de la lógica benemérita de conquista y San Bartolomé resultado y garante de la lógica colonial burocrática e institucional. El Rey, en ambos casos, premia a sus diferentes agentes coloniales de una manera similar, la concesión de unas becas propias y preferenciales, pero incidiendo en subrayar y remarcar sus autodefinidas y defendidas diferencias en el servicio prestado a la Corona. Esta realidad, además, supera la división tradicional presentada por la historiografía colombiana que muestra al colegio del Rosario como la institución encargada de la formación de las élites seculares mientras que San Bartolomé se dedicaba a los futuros sacerdotes. Una visión que no sólo limita a San Bartolomé a su realidad seminaria, obviando su condición múltiple, sino que homogeniza la naturaleza de las élites seculares.

Por tanto, la concreción de los colegiales reales bartolinos significa la cristalización de un escenario de poder institucional al interior de San Bartolomé y la refrendación de la fortaleza de las élites administrativas neogranadinas, conjugando el futuro de la institución educativa en un nuevo horizonte, esto es, un Seminario Conciliar y Colegio en manos de la Compañía y de las familias pertenecientes a los principales órganos administrativos de la audiencia de Santafé y del futuro virreinato. Un contexto de convivencia entre la Compañía y las familias pertenecientes al ejercicio administrativo de la mo-

71 Ramos Peñuela, 2009: 20-24. 
narquía, quiénes hacen de San Bartolomé el escenario de formación de sus descendientes, en muchos casos el futuro de esa misma administración neogranadina, de la mano de la propia orden jesuítica, configurando, por tanto, una suerte de patrimonialización dual y convenida de la institución académica. En este sentido, la expulsión jesuita de la dirección bartolina y de la gestión pedagógica de la formación de parte de la juventud neogranadina, fue, tal y como lo adelantaron los conjueces en el momento de proceder al extrañamiento, un inconveniente de unos pocos días; una celeridad que respondía al hecho de que la misma institucionalidad que llevó a cabo la expulsión era parte del Colegio Seminario desde hacía un siglo, por lo tanto, la continuidad de la institución, tal y como lo quería la Corona y los propios poderes administrativos, estaba asegurada. La nómina de los colegiales del San Bartolomé postjesuita nos muestra claramente esta continuidad. Así, los hijos de los ministros de la audiencia, la institución que había solicitado la transformación de la tipología colegial y la conversión de San Bartolomé en el escenario de materialización del premio a sus servicios prestados, seguían encabezando la relación de colegiales reales.

En este sentido, autores como Jaramillo Mejía, Groot, Pacheco y Restrepo, entre otros, nos presentan un San Bartolomé postjesuita sumido en el caos, desorganizado, desorientado y falto de la coherencia, templanza y modo de ser de la institución de la Compañía. Una visión que olvida la presencia activa de los poderes administrativos en el Colegio desde el siglo XVII, así como la convivencia y connivencia que existía entre la Compañía y los miembros de la institucionalidad desde el momento de su ingreso en las aulas bartolinas. La revisión de la documentación nos muestra que los únicos conflictos que se dieron entre el Colegio Seminario y los poderes seculares, entre la creación de las becas reales y la expulsión, se relacionan con la falta de pago de las pensiones de las becas, los 500 pesos de oro anuales - una ausencia de pagos relacionada con el incremento de los gastos del real erario en épocas de confrontaciones bélicas-, y cómo esto limitaba las posibilidades de la institución. Una institución que a pesar del no pago seguía educando y manteniendo a los colegiales reales ${ }^{72}$. Por tanto, no encontramos

72 «... luego de los atrasos y deudas, que con buena fe contrajo manteniendo a dichos colegiales [reales] (...) quedaron debiendo 3260 pesos con 2 reales y 6 maravedíes, correspondientes al reinado de SM Felipe Quinto (...) las becas de su real fundación a favor de sus ministros contadores y oficiales reales para que los hijos y descendientes de estos se críen y doctrinen en el tal colegio como se hace y se hizo en dicho tiempo de suspensión, supliendo en todo los alimentos y demás gastos hechos en los colegiales reales de dotación», Súplica del padre Jaime Torres S. J. al Rey para que se digne a mandar se pague al Colegio de San 
evidencias del malestar de la Compañía por la presencia y vinculación de los poderes administrativos al Colegio Seminario, sino más bien todo lo contrario, sobresale una labor conjunta e imbricada en la concepción y formación de los descendientes de la institucionalidad colonial neogranadina, que interrelaciona ambos escenarios de poder. Una apuesta dual por la continuidad que condicionó el futuro de la institución bartolina después del 1 de agosto de 1767.

Por tanto, sin entrar en el análisis de la transformación pedagógica y educativa, ni de la convulsión espiritual y sentimental que ésta supuso en la sociedad neogranadina, la abrupta salida de la Compañía no sólo no significó el fin del Colegio Seminario ni su ruptura total con la realidad precedente, ya que la institución que se hizo cargo de él, con el compromiso de que «en pocos días» todo volvería a la normalidad, ya era parte de él, tanto institucional como familiarmente, desde hacía un siglo, sino que desde en el momento de la expulsión y tras ésta, los padres y abuelos de los colegiales bartolinos se responsabilizaron de él, poniendo al frente de la gestión del mismo a los propios «hijos de la institución», aunque sin adscripción formal jesuita, pero apostando, dentro de la transformación, por la continuidad estructural, identitaria y familiar que llevaba un siglo siendo parte de la maquinaria de poder del Colegio Seminario de San Bartolomé.

Bartolomé lo que se debe del alimento y sustento de los colegiales reales, Santafé, 27 de marzo de 1767, AHJJMP, FPE, B1-ES1-EN1-CP26-DVD 01, doc. 1433. 


\begin{tabular}{|c|c|c|c|c|c|c|c|c|c|c|c|c|c|c|}
\hline $\begin{array}{l}\longleftarrow \\
Z\end{array}$ & 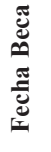 & $\stackrel{\text { I }}{\text { I }}$ & 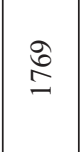 & $\frac{1}{\omega}$ & $\frac{5}{\omega}$ & 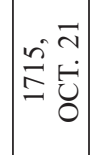 & 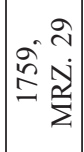 & $\stackrel{\infty}{\stackrel{\infty}{\Sigma}}$ & $\stackrel{尺}{\Xi}$ & $\begin{array}{l}\stackrel{0}{2} \\
\stackrel{2}{\infty} \\
\stackrel{2}{a}\end{array}$ & $\stackrel{\hat{\infty}^{\infty}}{=}$ & 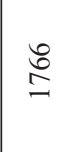 & 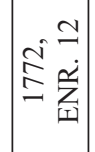 & 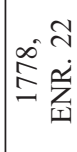 \\
\hline 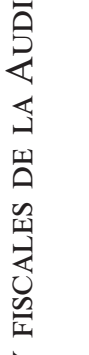 & 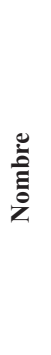 & 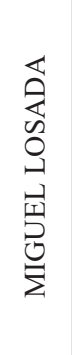 & 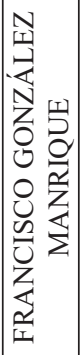 & 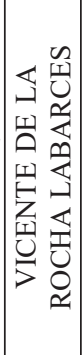 & 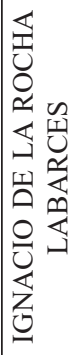 & 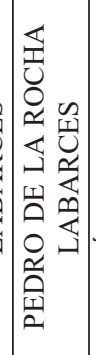 & 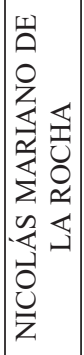 & 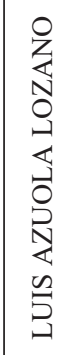 & 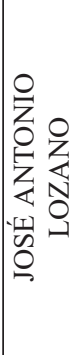 & 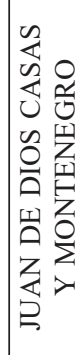 & 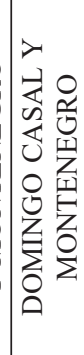 & 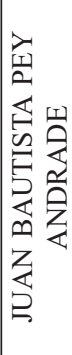 & 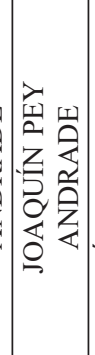 & 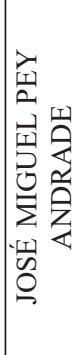 \\
\hline 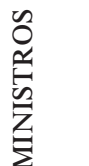 & 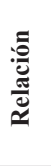 & 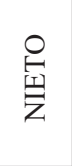 & $\stackrel{\varrho}{\varrho}$ & $\stackrel{\varrho}{g}$ & $\stackrel{\varrho}{\Theta}$ & $\stackrel{\varrho}{\stackrel{\Xi}{\Xi}}$ & 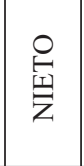 & 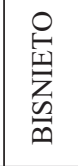 & $\stackrel{\varrho}{\stackrel{\Xi}{\Xi}}$ & $\stackrel{\varrho}{g}$ & $\stackrel{\varrho}{\Theta}$ & $\stackrel{\varrho}{\Theta}$ & $\stackrel{\varrho}{\ominus}$ & $\stackrel{\varrho}{g}$ \\
\hline 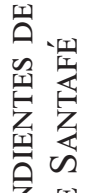 & 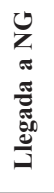 & $\begin{array}{l}0 \\
0 \\
0\end{array}$ & હે & & & $\hat{\infty}_{0}^{\infty}$ & & & 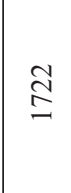 & & $\underset{I}{I}$ & & $\underset{I}{\stackrel{9}{I}}$ & \\
\hline 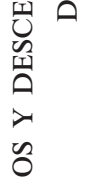 & 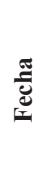 & 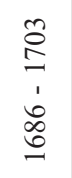 & 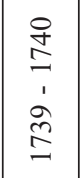 & & & 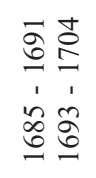 & & & $\begin{array}{l}\text { Iે } \\
\vdots \\
a \\
\Xi\end{array}$ & & \begin{tabular}{l}
$\bar{\infty}$ \\
\multicolumn{1}{c}{} \\
1 \\
$\vdots$ \\
$\vdots$ \\
\multicolumn{1}{|c|}{}
\end{tabular} & & $\begin{array}{l}\infty \\
\stackrel{0}{I} \\
1 \\
\infty \\
\stackrel{+}{I}\end{array}$ & \\
\hline 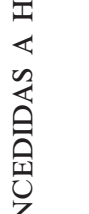 & 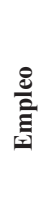 & 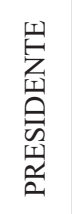 & 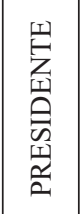 & & & 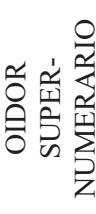 & & & $\begin{array}{l}\text { 号 } \\
\text { О人 }\end{array}$ & & 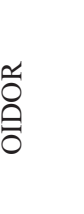 & & 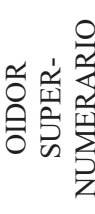 & \\
\hline 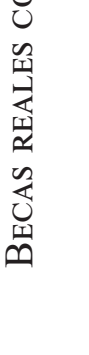 & 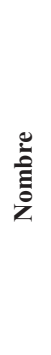 & 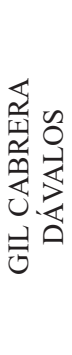 & 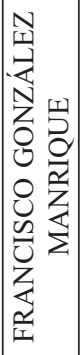 & & & 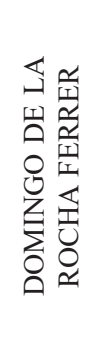 & & & 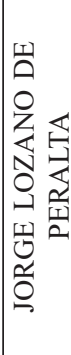 & & 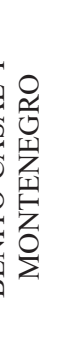 & & 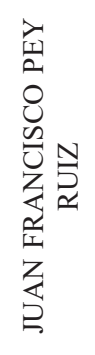 & \\
\hline
\end{tabular}




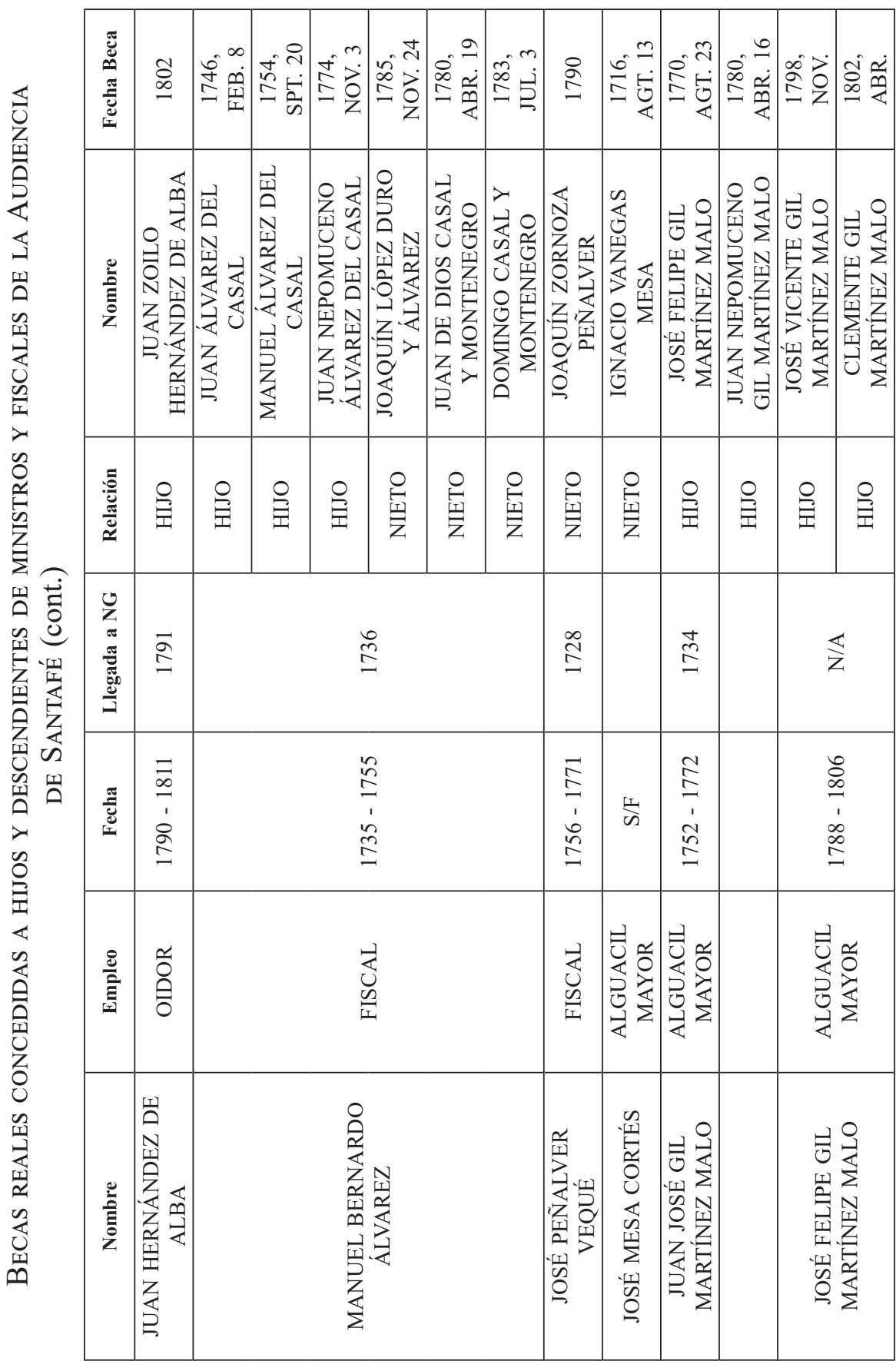




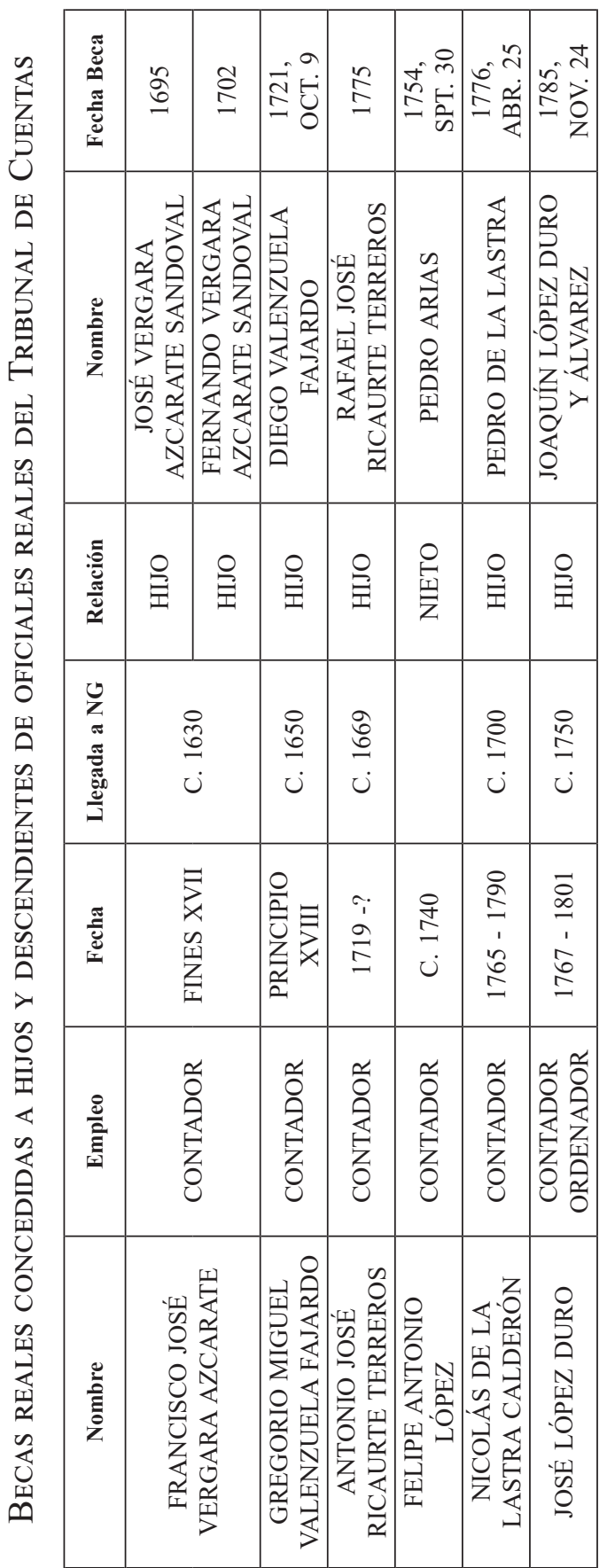




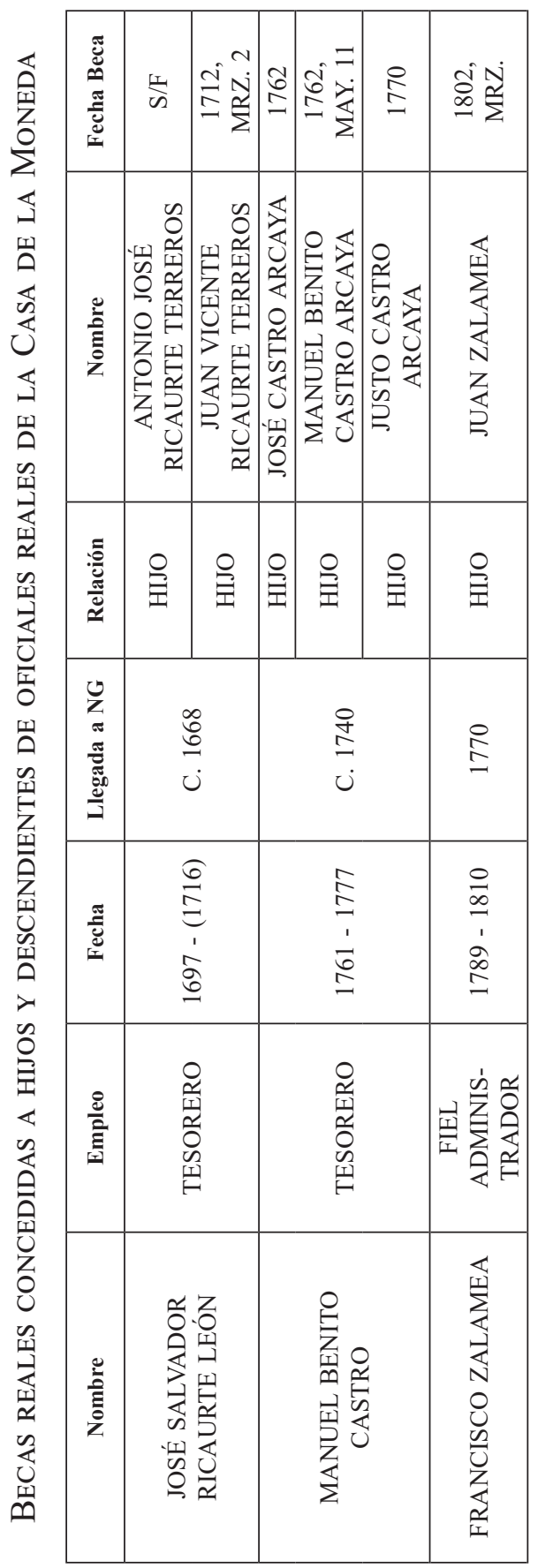

Revista de Indias, 2018, vol. LXXVIII, n. . 273, 459-503, ISSN: 0034-8341 https://doi.org/10.3989/revindias.2018.014 


\begin{tabular}{|c|c|c|c|c|c|c|c|c|c|c|c|c|c|c|c|}
\hline 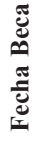 & $\left|\begin{array}{cc}0 & \\
0 & 0 \\
0 & 0 \\
-0 & 0\end{array}\right|$ & $\tilde{\sigma}$ & 约 & $\stackrel{1}{\varrho}$ & $\frac{1}{n}$ & 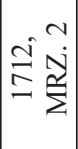 & 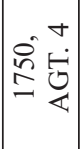 & $\hat{\imath}$ & 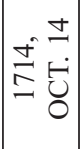 & 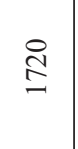 & 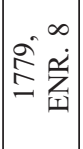 & $\underline{\Xi}$ & 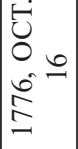 & શิ & $\stackrel{\widehat{a}}{I}$ \\
\hline 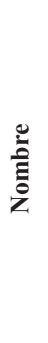 & 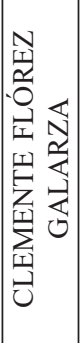 & 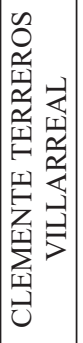 & 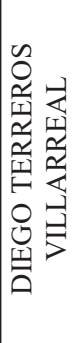 & 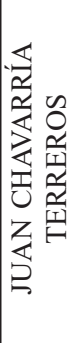 & 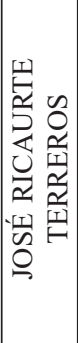 & 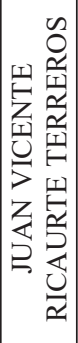 & 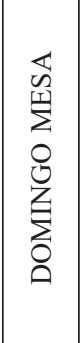 & 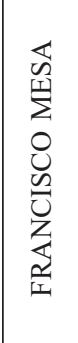 & 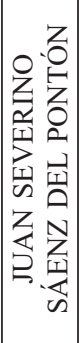 & 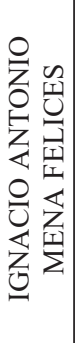 & 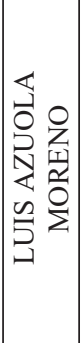 & 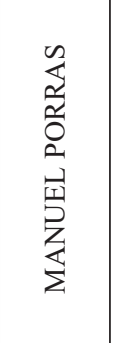 & 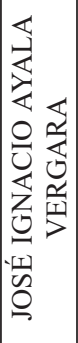 & 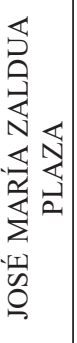 & 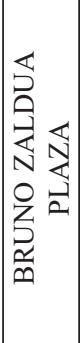 \\
\hline 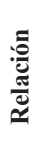 & $\stackrel{\bigcirc}{\Theta}$ & $\stackrel{\varrho}{\varrho}$ & $\stackrel{\varrho}{\Xi}$ & 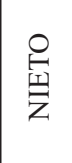 & 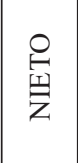 & $\begin{array}{l}\stackrel{0}{\ominus} \\
\stackrel{1}{\mathrm{~g}}\end{array}$ & $\stackrel{\bigcirc}{\Theta}$ & $\stackrel{\varrho}{\varrho}$ & 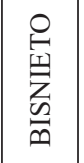 & $\stackrel{\varrho}{\varrho}$ & $\stackrel{\varrho}{\varrho}$ & $\stackrel{\varrho}{\varrho}$ & $\stackrel{\varrho}{\Theta}$ & $\stackrel{\varrho}{\Theta}$ & $\stackrel{\varrho}{\Theta}$ \\
\hline 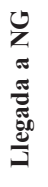 & & & & $\begin{array}{l}8 \\
0 \\
0 \\
\end{array}$ & & & 5 & je & $\begin{array}{l}\frac{8}{6} \\
\text { ن }\end{array}$ & & $\frac{\stackrel{ }{\Xi}}{i}$ & & $\frac{8}{\check{2}}$ & & \\
\hline 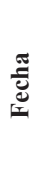 & & & & & & & & & & & & & $\begin{array}{l}\stackrel{ }{\Sigma} \\
\stackrel{1}{n} \\
\stackrel{\vec{n}}{\Xi}\end{array}$ & $\begin{array}{l}5 \\
5 \\
5 \\
5\end{array}$ & ì \\
\hline$\frac{8}{\stackrel{\Xi}{\pi}}$ & 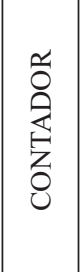 & & & 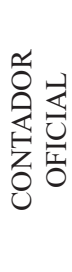 & & & 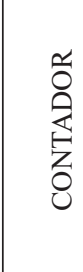 & 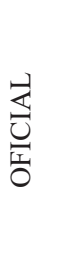 & 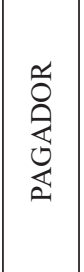 & 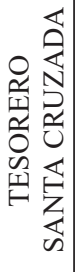 & 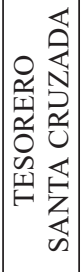 & 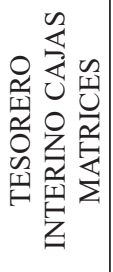 & 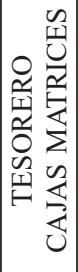 & 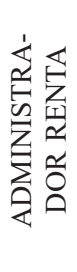 & 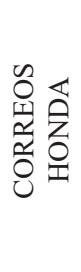 \\
\hline 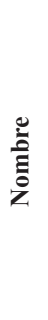 & 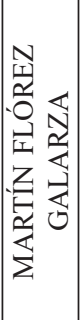 & & & 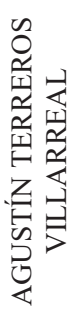 & & & 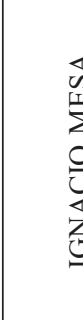 & 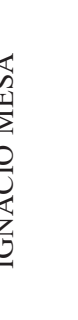 & 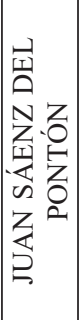 & 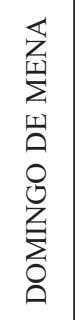 & 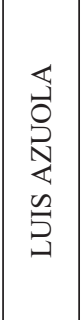 & 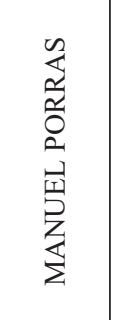 & 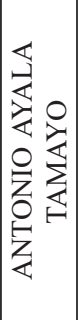 & 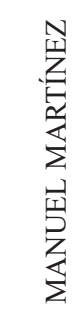 & 芯 \\
\hline
\end{tabular}




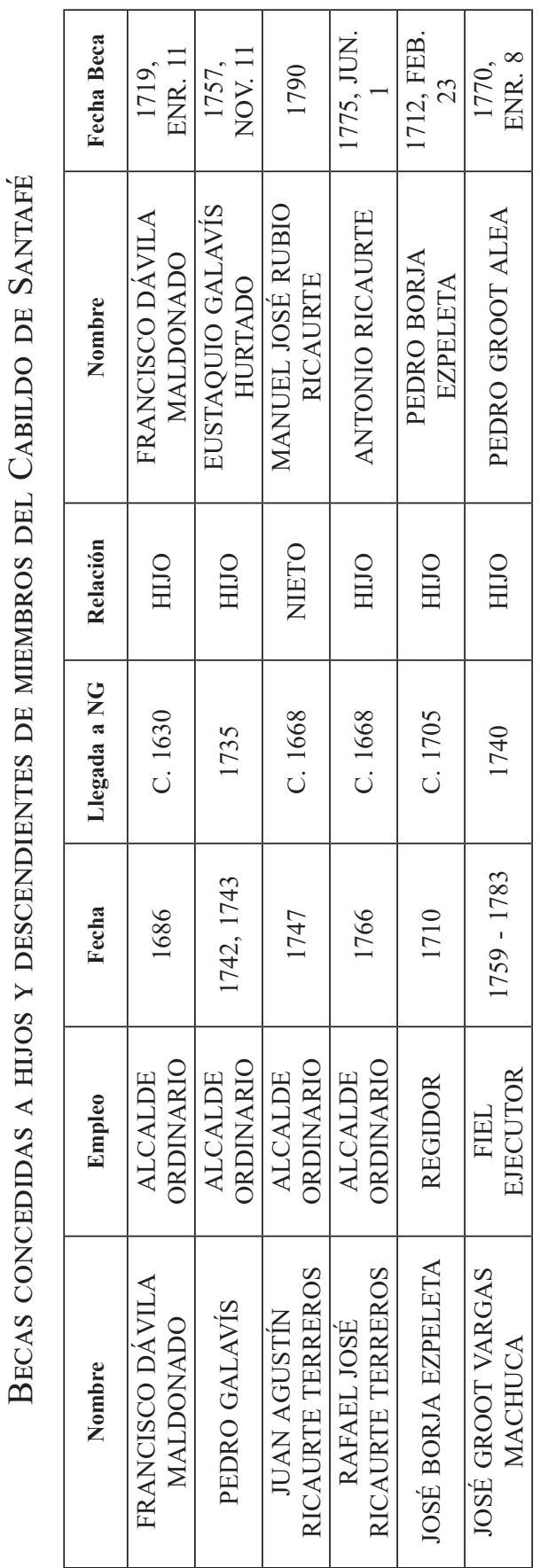

Revista de Indias, 2018, vol. LXXVIII, n. . 273, 459-503, ISSN: 0034-8341 https://doi.org/10.3989/revindias.2018.014 


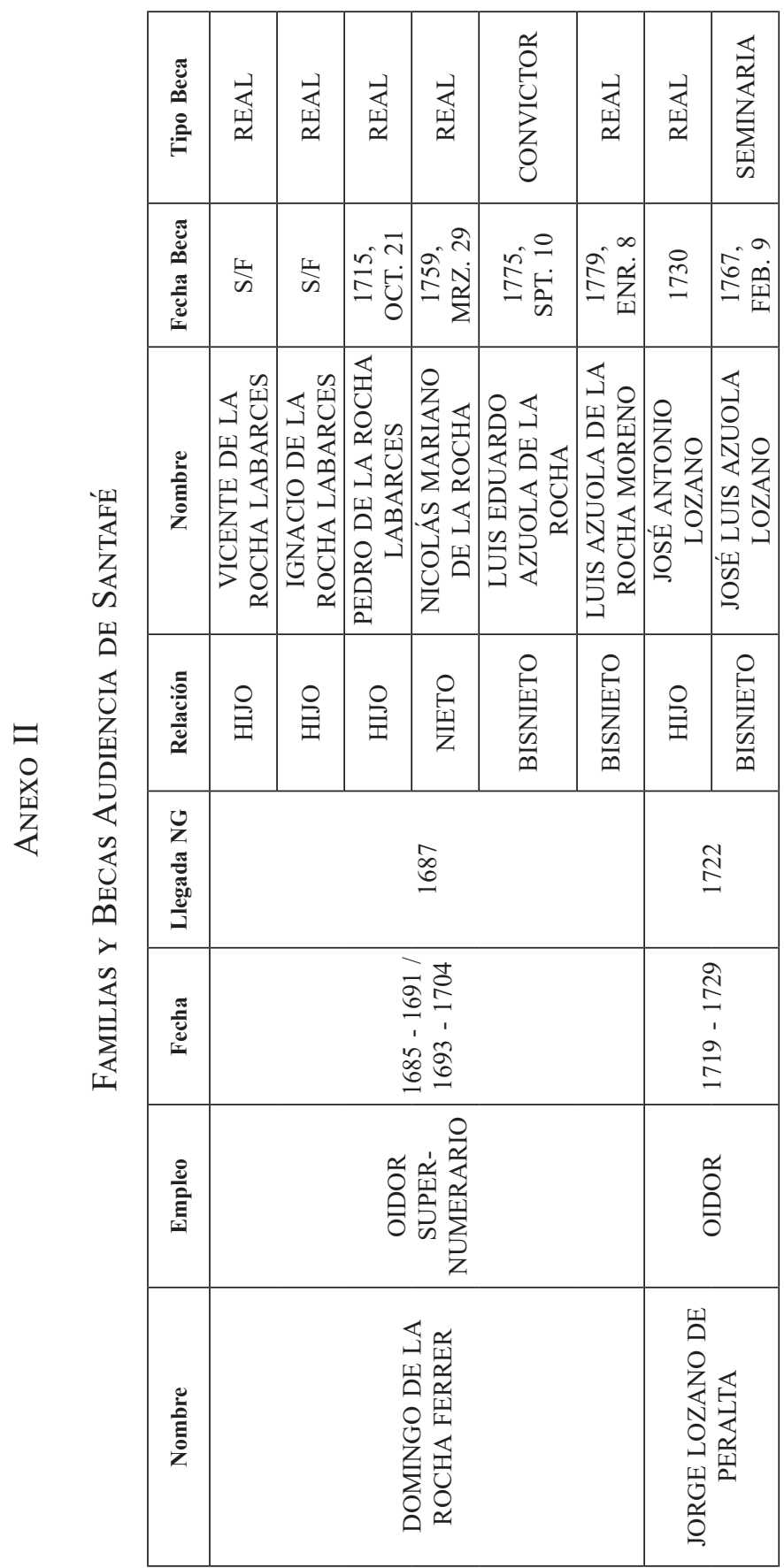




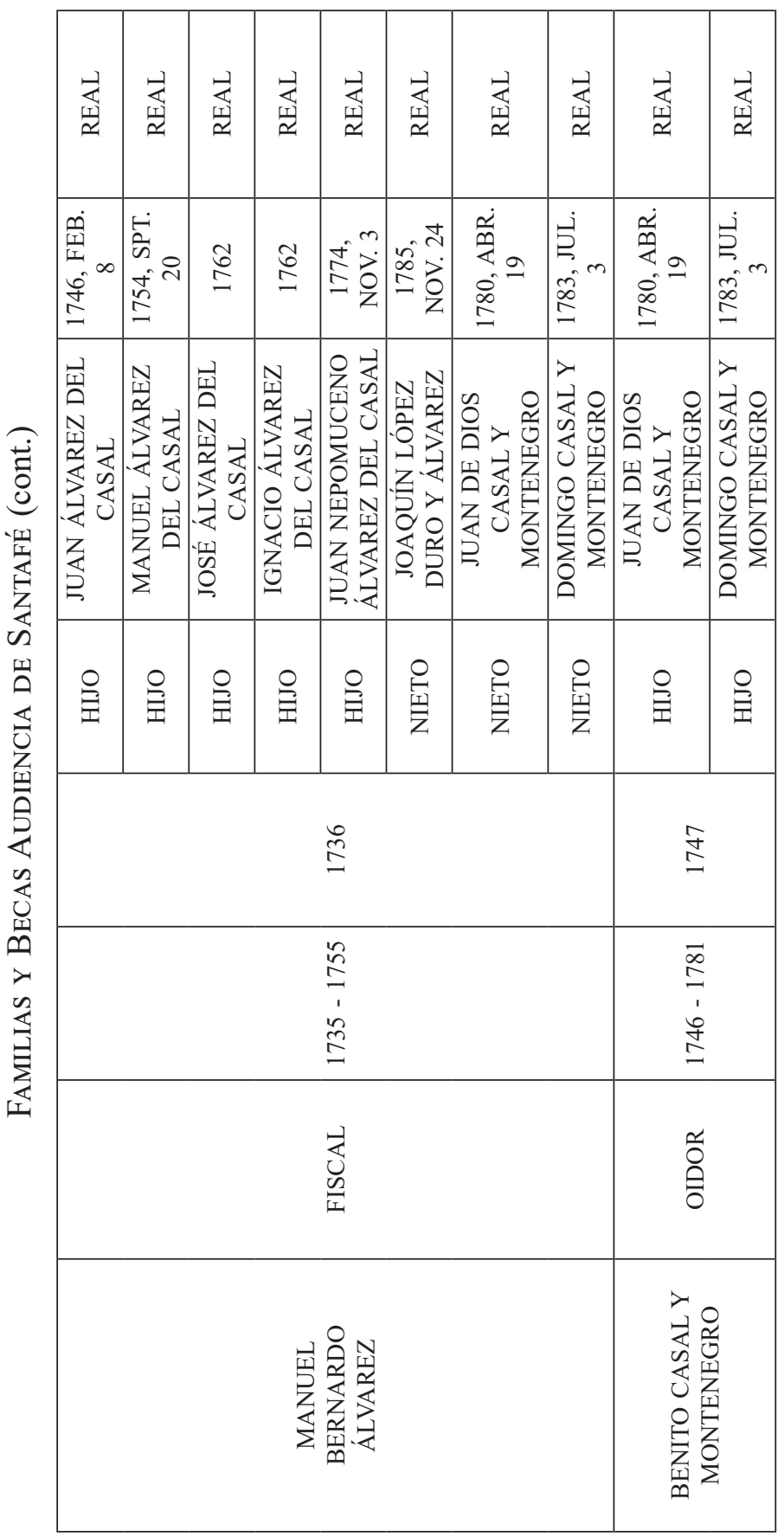

Revista de Indias, 2018, vol. LXXVIII, n. ${ }^{\circ} 273$, 459-503, ISSN: 0034-8341 https://doi.org/10.3989/revindias.2018.014 


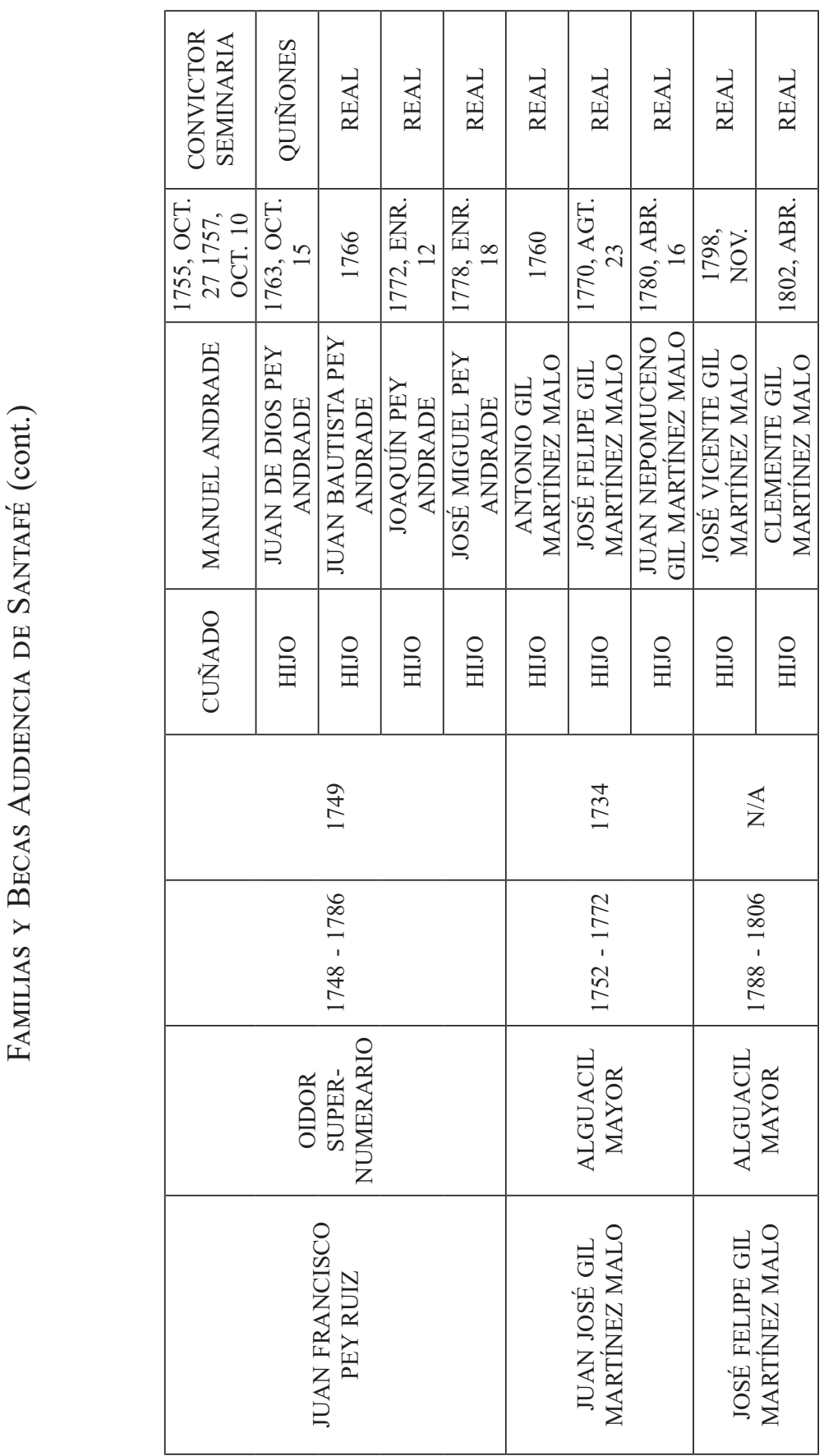



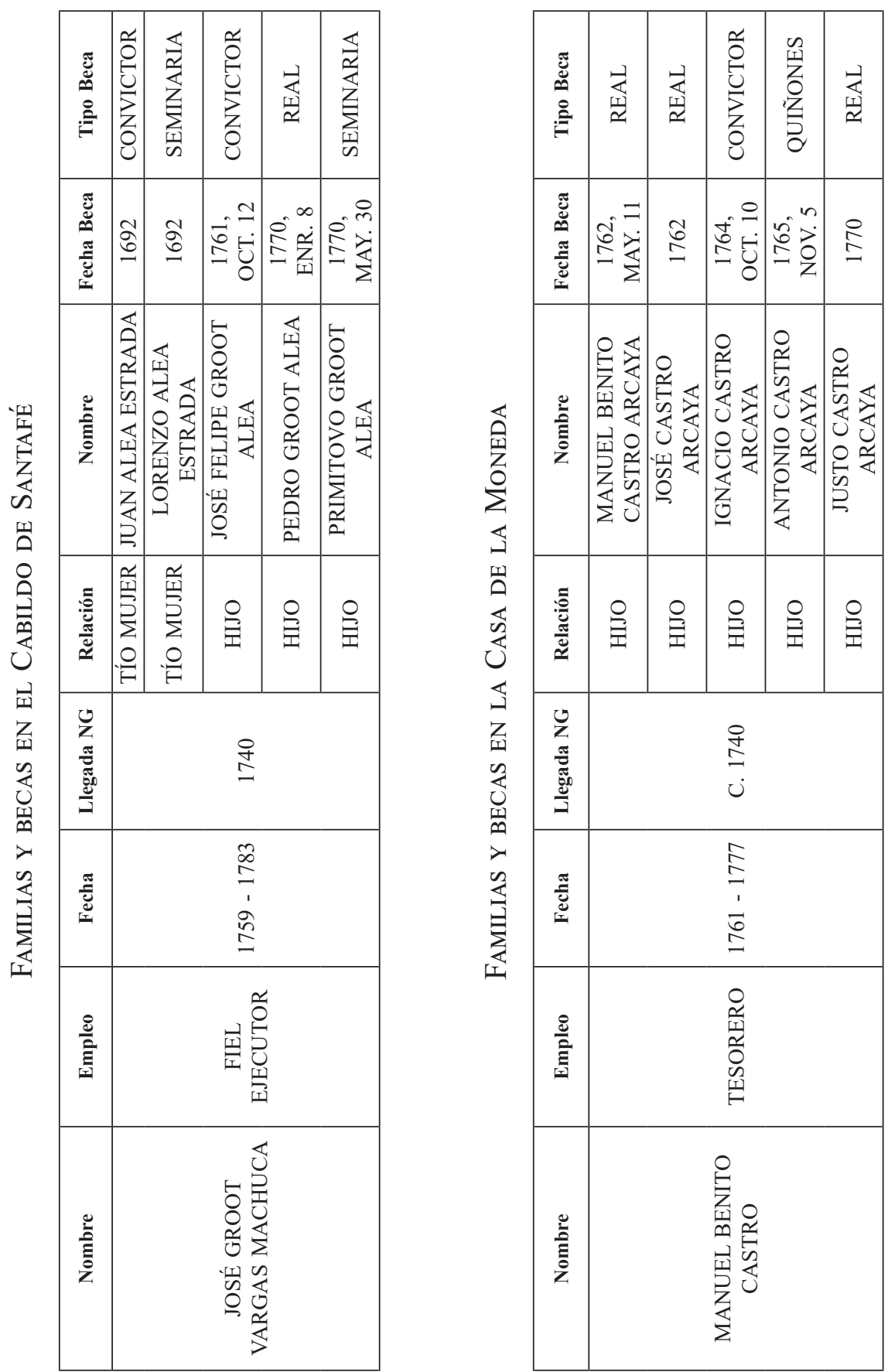


\begin{tabular}{|c|c|c|c|c|c|}
\hline 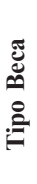 & 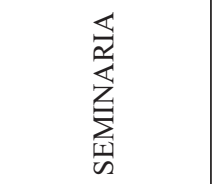 & 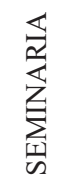 & 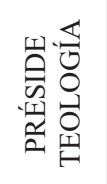 & 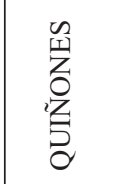 & 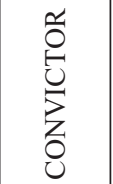 \\
\hline 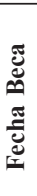 & $\begin{array}{l}\dot{\theta} \\
0 \\
\dot{\Xi}\end{array}$ & $\begin{array}{l}\text { 它 } \\
0 \\
\stackrel{n}{\Xi}\end{array}$ & $\begin{array}{l}\infty \\
\stackrel{1}{0} \\
\dot{n} \\
11 \\
\infty \\
\infty \\
\stackrel{0}{=}\end{array}$ & $\begin{array}{l}\stackrel{0}{-} \\
\ddot{0} \\
0 \\
0 \\
\stackrel{2}{=}\end{array}$ & 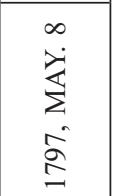 \\
\hline 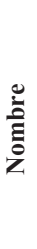 & 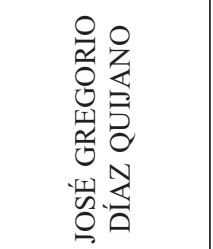 & 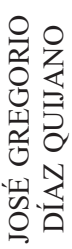 & 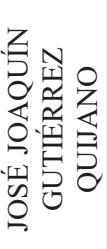 & 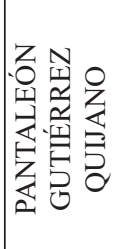 & 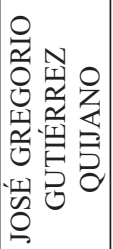 \\
\hline 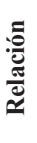 & $\stackrel{\bigcirc}{\stackrel{\Xi}{g}}$ & 㣽 & $\stackrel{\varrho}{\stackrel{\Xi}{\Xi}}$ & $\stackrel{\bigcirc}{\stackrel{\Xi}{\Xi}}$ & $\begin{array}{l}\stackrel{\ominus}{\ominus} \\
\stackrel{1}{\mid}\end{array}$ \\
\hline 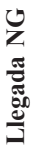 & $\underset{\dot{I}}{\stackrel{\Xi}{\Xi}}$ & \multicolumn{4}{|c|}{$\begin{array}{l}\text { 早 } \\
\text { ㄴ }\end{array}$} \\
\hline 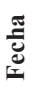 & & & & & \\
\hline 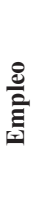 & 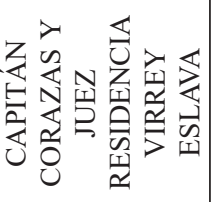 & \multicolumn{4}{|c|}{ 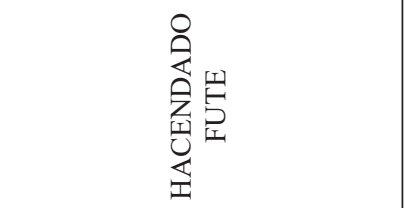 } \\
\hline 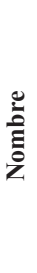 & 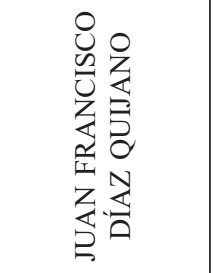 & \multicolumn{4}{|c|}{ 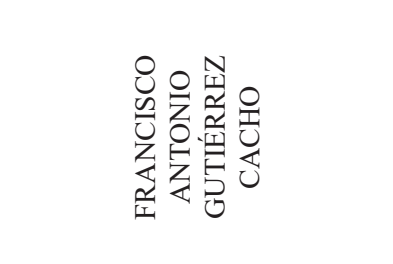 } \\
\hline
\end{tabular}




\begin{tabular}{|c|c|c|c|c|c|c|c|c|c|c|c|c|c|c|}
\hline 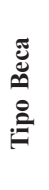 & 斑 & 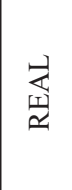 & 式 & 空 & 衤 & 鴍 & 这 & 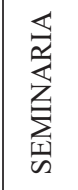 & 空 & 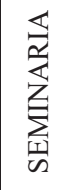 & 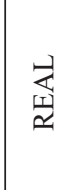 & 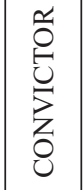 & 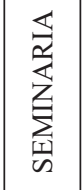 & 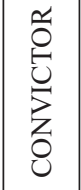 \\
\hline 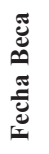 & $\stackrel{2}{6}$ & 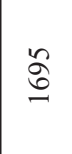 & $\stackrel{\hat{0}}{2}$ & $\frac{1}{\omega}$ & 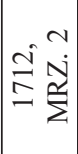 & $\frac{1}{\omega}$ & $\begin{array}{l}\stackrel{N}{\Sigma} \\
\stackrel{\mathbb{N}}{\Sigma}\end{array}$ & 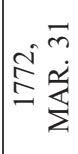 & $\stackrel{2}{\unrhd}$ & 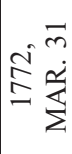 & 足方 & 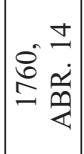 & 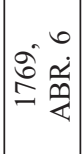 & $\begin{array}{l}\hat{D}^{n} \\
\stackrel{-}{a} \\
=\end{array}$ \\
\hline 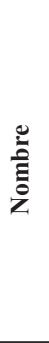 & 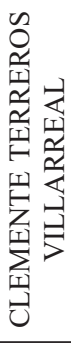 & 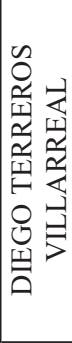 & 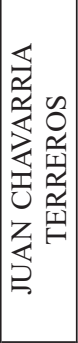 & 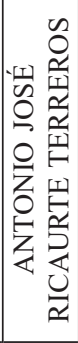 & 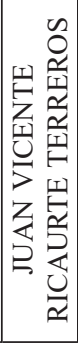 & 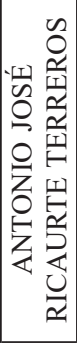 & 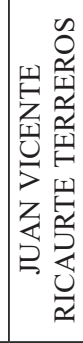 & 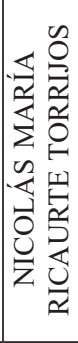 & 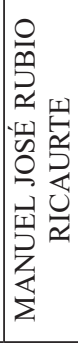 & 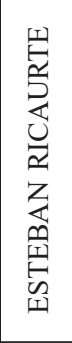 & 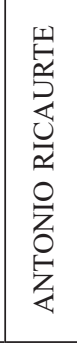 & 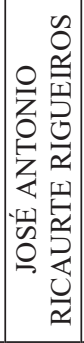 & 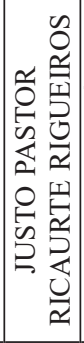 & 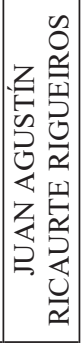 \\
\hline 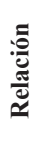 & $\stackrel{\varrho}{g}$ & $\stackrel{\varrho}{g}$ & $\begin{array}{l}\stackrel{0}{\ominus} \\
\stackrel{1}{Z}\end{array}$ & 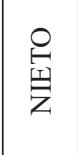 & 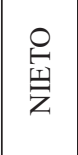 & 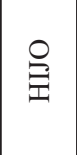 & 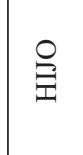 & $\stackrel{\circ}{\stackrel{\Xi}{\Xi}}$ & 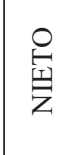 & $\stackrel{\varrho}{g}$ & $\stackrel{\varrho}{\Theta}$ & $\stackrel{\varrho}{\Theta}$ & $\stackrel{\circ}{\stackrel{\Xi}{\Xi}}$ & $\stackrel{\varrho}{\Theta}$ \\
\hline 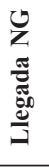 & \multicolumn{5}{|c|}{ ن } & \multicolumn{2}{|c|}{$\begin{array}{l}\infty \\
\stackrel{0}{0} \\
0 \\
ن\end{array}$} & \multicolumn{2}{|c|}{$\begin{array}{l}\infty \\
\stackrel{0}{0} \\
\dot{0}\end{array}$} & \multicolumn{2}{|c|}{$\begin{array}{l}\infty \\
\stackrel{0}{0} \\
0 \\
ن\end{array}$} & \multicolumn{3}{|c|}{$\begin{array}{l}\infty \\
\stackrel{0}{0} \\
ن \\
ن\end{array}$} \\
\hline 吾 & & & & & & & 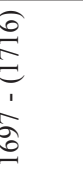 & \multicolumn{2}{|c|}{ 吉 } & \multicolumn{2}{|c|}{ 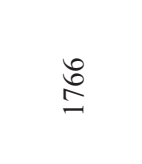 } & \multicolumn{3}{|c|}{ 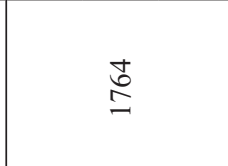 } \\
\hline 离 & \multicolumn{5}{|c|}{ 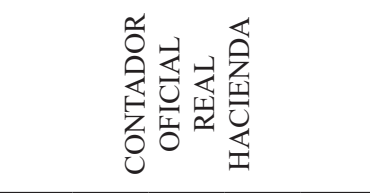 } & \multicolumn{2}{|c|}{ 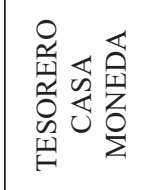 } & \multicolumn{2}{|c|}{ 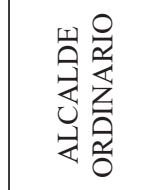 } & \multicolumn{2}{|c|}{ 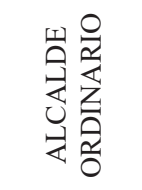 } & \multicolumn{3}{|c|}{ 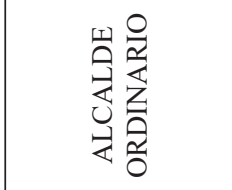 } \\
\hline 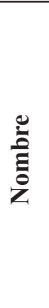 & \multicolumn{5}{|c|}{ 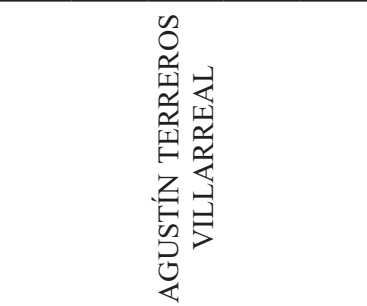 } & \multicolumn{2}{|c|}{ 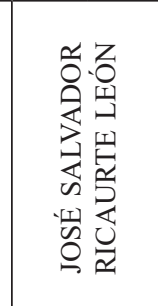 } & \multicolumn{2}{|c|}{ 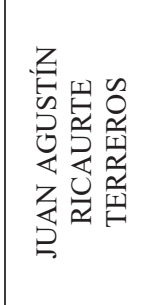 } & \multicolumn{2}{|c|}{ 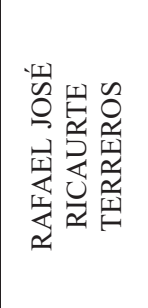 } & \multicolumn{3}{|c|}{ 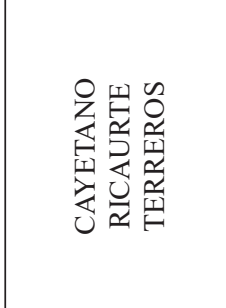 } \\
\hline
\end{tabular}




\section{BiBLIOGRAFÍA}

Bertran-Quera, Miguel S. J., La pedagogía de los jesuitas en la Ratio Studiorum. La fundación de Colegios. Orígenes, autores y evolución histórica de la Ratio. Análisis de la educación religiosa, caracterológica e intelectual, Caracas, Arte, 1984.

Burkholder, Mark y Chandler, David S., Biographical dicctionary of audiencia ministers in The Americas, 1687-1821, Westport, Greenwood Press, 1982.

Delgado Criado, Buenaventura (coord.), Historia de la educación en España y América, Madrid, SM y Morata, 1993.

Ferrer Benimeli, José Antonio S. J., De la expulsión a la extinción de la Compañía de Jesús, Madrid, Fundación Histórica Tavera, Digibis, 2000.

Ferrer Benimeli, José Antonio S. J., "La expulsión de los jesuitas", Jorge Enrique Salcedo Martínez, S. J. (ed.), Los jesuitas expulsados, extinguidos y restaurados. Memorias del Primer Encuentro Internacional sobre la historia de la Compañía de Jesús, Bogotá, Ed. P. Universidad Javeriana, 2014: 67-119.

Flórez de Ocáriz, Juan, Genealogías del Nuevo Reino de Granada, Madrid, 1674. Edición facsimilar, 3 vols., Bogotá, Instituto Caro y Cuervo/Instituto Colombiano de Cultura Hispánica, 1990.

Gamboa Mendoza, Jorge, Economía, identidad y poder: la construcción de la identidad de los conquistadores y encomenderos del Nuevo Reino de Granada, vista a través de las probanzas de mérito y servicios (1550-1650), Bogotá, ICANH, 2002.

Gamboa Mendoza, Jorge, El precio de un marido, Bogotá, ICANH, 2003

García Cárcel, Ricardo (coord.), Historia de España en el siglo XVIII. La España de los Borbones, Madrid, Cátedra, 2003. Historia Serie Mayor.

Gil, Eusebio (ed.), La pedagogía de los jesuitas, ayer y hoy, Madrid, CONEDSI/ Universidad Pontificia de Comillas, 2002.

Groot, José Manuel, Historia Eclesiástica y Civil de la Nueva Granada, 3 vols., Bogotá, Casa Editorial de M. Rivas y Cía., 1869.

Guasti, Niccoló, "La pieza clave antijesuitismo español del siglo XVIII: el 'Dictamen fiscal de expulsión de los jesuitas' de Pedro Rodríguez de Campomanes", Susana Monreal, Sabina Pavone y Guillermo Zermeño (coords.), Antijesuitismo y filojesuitismo. Dos identidades antes la Restauración, México, U. Iberoamericana, 2014: 77-106.

Guillén de Iriarte, María Clara, Nobleza e Hidalguía. Colegio Mayor del Nuestra Señora del Rosario, 1651-1820, 2 vols., Bogotá, Colegio Mayor de Nuestra Señora del Rosario/Instituto Colombiano de Cultura Hispánica, 1994. 
Hernández de Alba, Guillermo, Documentos para la historia de la educación en Colombia, Bogotá, Patronato Colombiano de Artes y Ciencias/Colegio Máximo de las Academias de Colombia, 1969.

Jaramillo Mejía, William, Real Colegio Mayor y Seminario de San Bartolomé. Nobleza e hidalguía. Colegiales de 1605 a 1820, Bogotá, Instituto Colombiano de Cultura Hispánica, 1996.

Lynch, John, La España del siglo XVIII, Barcelona, Crítica, 1991.

Marín Leoz, Juana María, Gente decente. La élite rectora de la capital, 1797-1803, Bogotá, ICANH, 2008.

Marín Leoz, Juana María, “«Virtud, letras y conocida sangre; siendo hijo de muy buenos padres». Informaciones de los colegiales de San Bartolomé, 1689-1808”, Normatividades e instituciones eclesiásticas en Iberoamérica. Volúmenes: Nueva España, Perú, Nuevo Reino de Granada, Frankfurt, Max-Planck-Institut für europäische Rechtsgeschichte/Instituto Max Planck para la historia del derecho europeo, 2015.

O’Neill, Charles E. S. J. (dir.), Dicccionario histórico de la Compañía de Jesús. Biográfico-temático, Roma, Institutum Historicum, 2001.

Pacheco, Juan Manuel S. J., Los Jesuitas en Colombia, 3 vols., Bogotá, San Juan Eudes, 1959.

Pérez Puente, Leticia, "La fundación del seminario conciliar y el fortalecimiento de la jurisdicción episcopal (Lima 1564-1603)”, Rodolfo Aguirre Salvador (coord.), Espacios de saber. Espacios de poder: iglesia, universidades y colegios en Hispanoamérica, siglos XVI-XIX, México, Universidad Nacional Autónoma de México, 2013: 85-115.

Ramos Peñuela, Aristides, "Criollos: configuración de una identidad", Aristides Ramos Peñuela, Óscar Saldarriaga y Radamiro Gaviria (eds.), El Nuevo Reino de Granada y sus provincias. Crisis de Independencia y experiencias republicanas, Bogotá, Editorial Universidad del Rosario y Pontificia Universidad Javeriana, 2009: 16-30.

Restrepo, Daniel S. J., El Colegio de San Bartolomé. El Colegio a través de nuestra historia. Galería de hijos insignes del Colegio, Bogotá, Sociedad Editorial, 1928.

Restrepo Posada, José, Arquidiócesis de Bogotá. Datos biográficos de sus prelados, Bogotá, Lumen Christi, 1961.

Rey Fajardo, José del S. J., "La implantación del Ratio Studiorum en la provincia del Nuevo Reino de Granada", Revista Portuguesa de Filosofía, 55 (Braga, 1999): 275-317.

Rey Fajardo, José del S. J., La facultad de lenguas en la Universidad Javeriana colonial y la república de las letras neogranadinas, Bogotá, Editorial el Búho, 2010 . 
Rey Fajardo, José del S. J., Libro de grados de la Universidad y Academia, 2 vols., Bogotá, Editorial Universidad Javeriana, 2013.

Rey Fajardo, José del S. J., Expulsión, extinción y restauración de los Jesuitas en el Nuevo Reino de Granada (1767-1815), Bogotá, P. Universidad Javeriana, 2014.

Rey Fajardo, José del S. J. y González Mora, Felipe, Los Jesuitas en Antioquia 17271767. Aportes a la Historia de la Cultura y el Arte, Bogotá, Pontificia Universidad Javeriana, 2008.

Rodríguez Cruz, Águeda María, La Universidad en la América Hispana, Madrid, MAPFRE, 1992.

Salazar, Abel José, Los estudios eclesiásticos superiores en el Nuevo Reino de Granada, Madrid, CSIC/Instituto Santo Toribio Mogroviejo, 1946.

Silva Olarte, Renán, Los ilustrados de Nueva Granada 1760-1808. Genealogía de una comunidad de interpretación, Medellín, Fondo Editorial Universidad EAFIT, 2002.

Silva Olarte, Renán, Saber, cultura y sociedad en el Nuevo Reino de Granada, siglos XVII-XVIII, Medellín, La Carreta, 2004.

Silva Olarte, Renán, La ilustración en el virreinato de la Nueva Granada. Estudios de historia Cultural, Medellín, La Carreta, 2005.

Soto Arango, Diana, La reforma del Plan de Estudios del Fiscal Moreno y Escandón (1774-1779), Bogotá, Universidad del Rosario, 2004a.

Soto Arango, Diana, "La secularización de los estudios superiores de Santafé y Mompox”, Diana Soto Arango (ed.), Estudios sobre la universidad latinoamericana desde la Colonia hasta el siglo XXI. Reformas universitarias, Bogotá, Rude Colombia, 2004b: 43-59.

Vázquez Varela, Ainara, “De la primera sangre de este reino”. Las élites dirigentes de Santa Fe, 1700-1750, Bogotá, Editorial Universidad del Rosario, 2010.

Vergara Ciordia, Javier, "Datos y fuentes para el estudio de los seminarios conciliares en Hispanoamérica: 1536-1800", Anuario de Historia de la Iglesia, 14 (Pamplona, 2005): 239-300.

Villalba Pérez, Enrique, Consecuencias educativas de la expulsión de los Jesuitas de América, Madrid, Biblioteca del Instituto Antonio Nebrija de Estudios sobre la Universidad/ Universidad Carlos III, 2003.

Fecha de recepción: 17 de octubre de 2015.

Fecha de envío de las modificaciones: 19 de febrero de 2016.

Fecha de aceptación: 19 de marzo de 2016. 


\section{Institutional framework and power. The expulsion of the Society of Jesus and the Royal College and Seminar of San Bartolome in Santafé de Bogotá}

The expulsion of the Society of Jesus from the New Kingdom of Granada on 1 August, 1767, did not put an end to San Bartolomé Seminar which had been under the Company's rule since its foundation in 1605. In this paper, the circumstances and causes that contributed to that continuity are analysed, using documents held at the Javeriano Historical Archive Juan Manuel Pacheco SJ, and specifically the information related to the creation of the Royal Bartolino Fellowships in 1604, the collegiate fellows, and the incorporation of the Santa $\mathrm{Fe}$ administrative elites into the institution. An examination of the dual administration of the Seminar from 1767 onwards shows this to have been an essential part of its continuity.

KEY WORDS: Jesuit expulsion; colleges; administrative elites; royal fellowships; institutions. 